
Würzburger Vorträge zur Rechtsphilosophie, Rechtstheorie und Rechtssoziologie

Herausgegeben von Horst Dreier und Dietmar Willoweit

Begründet von Hasso Hofmann, Ulrich Weber und Edgar Michael Wenz ${ }^{\dagger}$

Heft 27 


\section{Wolfgang Huber}

Rechtfertigung und Recht

Über die christlichen Wurzeln der europäischen Rechtskultur 
Vortrag gehalten am 9. Februar 2000

Die Deutsche Bibliothek - CIP-Einheitsaufnahme

Ein Titeldatensatz für diese Publikation ist bei

Der Deutschen Bibliothek erhältlich. (http://www.ddb.de)

ISBN 3-7890-7022-X
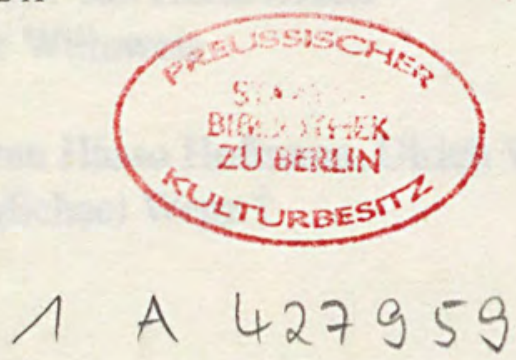

1. Auflage 2001

C Nomos Verlagsgesellschaft, Baden-Baden 2001. Printed in Germany. Alle Rechte, auch die des Nachdrucks von Auszügen, der photomechanischen Wiedergabe und der Übersetzung, vorbehalten. Gedruckt auf alterungsbeständigem Papier.

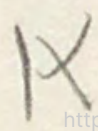




\section{Die Frage nach der Begründbarkeit des Rechts}

„Wir hofften auf Gerechtigkeit und bekamen den Rechtsstaat.“ Mit diesen Worten hat die Bürgerrechtlerin Bärbel Bohley im Jahr 1992 ihrer Enttäuschung darüber Luft gemacht, daß der Rechtsstaat nicht unmittelbar zur Gerechtigkeit führt. ${ }^{1}$ Der mit der Vereinigung Deutschlands verbundene Übergang zum demokratischen Rechtsstaat wurde gerade von oppositionellen Bürgerrechtlern in der damaligen DDR mit großen Erwartungen begleitet. Soweit sie das mit der Hoffnung verbanden, der Rechtsstaat verbürge zugleich die Gerechtigkeit, war die Enttäuschung unausweichlich. Denn der Übergang zum demokratischen Rechtsstaat hat keineswegs unmittelbar alle Gerechtigkeitsprobleme gelöst. Vergleichbare Erfahrungen blieben auch in anderen Ländern Mittel- und Osteuropas nicht aus, die seit 1989 den Übergang zu Demokratie und Rechtsstaat vollzogen haben. Aber auch in Ländern mit einer langen rechtsstaatlichen Tradition ist es nicht anders. Wichtige Forderungen der Gerechtigkeit bleiben uneingelöst. Besonders verwirrend mußte es in den mittel- und osteuropäischen Transformationsgesellschaften wirken, daß überwunden geglaubte Gerechtigkeitsprobleme sich auch wieder neu stellen können. Das Problem der Arbeitslosigkeit ist dafür das wichtigste Beispiel.

Auf solche Erfahrungen kann mit Zynismus reagiert werden. Das ist dort der Fall, wo erklärt wird, unter marktwirtschaftlichen und zugleich rechtsstaatlichen Bedingungen nach Gerechtigkeit auch nur zu fragen, sei bereits verfehlt. Denn Gerechtigkeit sei gar kein mögliches Ziel gesellschaftlichen Handelns. Wer anderes behaupte, verfalle einer bloßen Ideologie. Friedrich August von Hayek hat diese These besonders nachdrücklich vertreten. ${ }^{2}$ Er hat sich dabei den Umstand zunutze gemacht, daß die Rede von der „sozialen Gerechtigkeit“ sich durch ein hohes Maß an Unschärfe auszeichnet; deshalb kommt es in der Tat häufig vor, daß der Begriff der ,sozialen Gerechtigkeit“ zur Legitimation der jeweils eigenen Interessen eingesetzt wird.

1 Bärbel Bohley, in: DIE ZEIT 14/1992, 44.

2 Vgl. z. B. F. A. von Hayek, Recht, Gesetzgebung und Freiheit, Bd. 2: Die Illusion der sozialen Gerechtigkeit, Landsberg am Lech 1981. 
Fragt man jedoch nach dem Zusammenhang von Gerechtigkeit und Recht, dann läßt sich mehr Präzision erreichen. ${ }^{3}$ Es zeigt sich dann nämlich, daß der Begriff des Rechts stets in den Zusammenhang mit bestimmten Begründungsprinzipien gerückt wurde. Der Zusammenhang von Gerechtigkeit und Recht ist dafür ein besonders markantes Beispiel.

In der Tradition der philosophischen wie der theologischen Rechtsethik wird der Zusammenhang zwischen beiden zunächst dahingehend bestimmt, daß die Befolgung des Rechts zugleich als Erfüllung der Gerechtigkeit anerkannt wird. Gerechtigkeit wird dann im formalen Sinn als iustitia legalis betrachtet. Wird dagegen das Recht verletzt, so tritt die Gerechtigkeit in ihrer wiederherstellenden und korrigierenden Funktion in den Blick. Sie wirkt als iustitia correctiva. So formal beide Begriffe sind, so kann man nicht bezweifeln, daß jedes menschliche Zusammenleben auf diesen doppelten Aspekt des Zusammenhangs von Recht und Gerechtigkeit angewiesen ist.

Den entscheidenden Schritt über den Begriff der formalen Gerechtigkeit hinaus hat Aristoteles mit seiner bahnbrechenden Unterscheidung zwischen austeilender und ausgleichender Gerechtigkeit getan. Er sieht darin die beiden entscheidenden Charakteristika der materialen Gerechtigkeit. Austeilend oder distributiv ist sie aus der Perspektive des Gemeinwesens, das jeder und jedem einzelnen diejenigen Rechte zuweist, die ihr oder ihm kraft des Status oder der Verdienste der Person zukommen. Unterschiedliche Bürgerrechte, die unterschiedliche Rechtsstellung von Männern und Frauen eingeschlossen, hat Aristoteles mit diesem Begriff der Gerechtigkeit für vereinbar angesehen. Ausgleichend oder kommutativ ist die Gerechtigkeit aus der Perspektive von zwei oder mehr Rechtssubjekten, die miteinander einen Vertrag abschließen - beispielsweise einen Kauf- oder einen Arbeitsvertrag. Der gerechte Preis und der gerechte Lohn sind die entscheidenden Beispiele für diese Sphäre der ausgleichenden Gerechtigkeit.

3 Vgl. dazu ausführlicher vom Verf., Gerechtigkeit und Recht. Grundlinien christlicher Rechtsethik, Gütersloh 1996, 2. Aufl. 1999. 
Die neuere Diskussion hat neben diese beiden auf Aristoteles zurückgehenden Momente der materialen Gerechtigkeit ein drittes Moment gestellt, das als Beteiligungsgerechtigkeit bezeichnet wird. Neben die distributive und die kommutative tritt damit die kontributive Gerechtigkeit. Auf Beteiligung ausgerichtet ist die Gerechtigkeit aus der Perspektive der einzelnen, die ihren Beitrag zum Gemeinwesen leisten, ihre Begabungen konstruktiv einsetzen und auch im Blick auf den eigenen Lebensunterhalt das ihnen Mögliche tun wollen. Es ist kein Zufall, daß dieses Moment der kontributiven Gerechtigkeit in einer Zeit die Aufmerksamkeit auf sich gezogen hat, in welcher durch hohe Arbeitslosigkeit ganze Bevölkerungsgruppen von der Möglichkeit aktiver Beteiligung ausgeschlossen sind und jedenfalls im Bereich der organisierten Erwerbsarbeit keine Chancen haben, ihre eigenen Begabungen einzubringen und ihren Lebensunterhalt durch eigene Leistung zu sichern.

Nun ist mit diesen terminologischen Unterscheidungen noch längst nicht gesagt, was theologisches Nachdenken zum Verhältnis von Gerechtigkeit und Recht beizutragen hat. Schaut man auf die biblische Rede von Gerechtigkeit, der hebräischen sedaqa beziehungsweise der griechischen dikaiosyne, so stößt man bei allen Unterschieden zwischen dem alttestamentlichen und dem neutestamentlichen Befund auf einen Grundzug, der sich mit einem Ausdruck von Jan Assmann als „konnektive Gerechtigkeit" bezeichnen läßt. ${ }^{4}$ Gerechtigkeit ist ein Verhältnisbegriff; er hat es mit der Verknüpfung von Lebenssphären zu tun; er zielt auf Verhältnisse wechselseitiger Anerkennung. Gerechtigkeit bezieht sich zuallererst auf das Verhältnis Gottes zum Menschen, auf Gottes zurechtbringende Gerechtigkeit, die im dankbaren Bekenntnis der Glaubenden und in ihrer Treue zu Gottes Weisung ihre Antwort findet. Von hier aus beschreibt Gerechtigkeit sodann eine Ordnung der Beziehungen zwischen den Menschen auf der Grundlage wechselseitiger Anerkennung. Dabei ist der biblische $\mathrm{Be}$ griff der Gerechtigkeit vom Begriff der Barmherzigkeit nicht abzulö-

4 Vgl. J. Assmann, Ma'at. Gerechtigkeit und Unsterblichkeit im alten Ägypten, München 1990. 
sen; die Gerechtigkeit hat deshalb immer am vorrangigen Eintreten für die Schwächeren, für die Opfer von Ungerechtigkeit, ihren entscheidenden Maßstab. Vor allem aber ist der biblische Begriff der Gerechtigkeit durch einen eschatologischen Überschuß geprägt; jede menschliche Rechtsordnung trägt deshalb einen vorläufigen und überbietbaren Charakter. Aus einer solchen Perspektive bleibt nicht unerklärlich, warum mit der Einführung des Rechtsstaats nicht schon die Gerechtigkeit verwirklicht ist. Bärbel Bohleys Seufzer, mit dem unsere Überlegung einsetzte, läßt sich deshalb auch so wenden: Wir erhoffen Gerechtigkeit; deshalb achten wir den Rechtsstaat und bemühen uns um eine Verbesserung des Rechts.

Das geltende Recht ist zwar von den unterschiedlichen Formen seiner inhaltlichen Begründung unterschieden; aber es läßt sich nicht von ihnen trennen. Der Zusammenhang zwischen dem Recht und den es tragenden Begründungsprinzipien ist historisch vermittelt. Daraus erklärt sich zunächst die prägende Bedeutung des jüdisch-christlichen Rechtsdenkens für die europäische Rechtskultur. Der Hinweis auf diese Bedeutung des jüdisch-christlichen Rechtsdenkens ist jedoch nicht nur von historischem Belang. Die Erinnerung daran ist vielmehr auch für die Weiterentwicklung unserer Rechtskultur relevant. Das soll im Folgenden am Leitfaden des inneren Zusammenhangs von Rechtfertigung und Recht verdeutlicht werden.

Dabei betrachte ich das Recht als ein Instrument der gesellschaftlichen Gestaltung und Konfliktregelung, welches auf der Grundlage wechselseitiger Anerkennung beruht. Was es mit dem Recht insgesamt auf sich hat, kommt insofern in der neuzeitlichen Idee der Menschenrechte unüberbietbar klar zum Ausdruck. Denn sie statuieren eine unaufhebbare Würde und eine unhintergehbare Rechtsstellung der einzelnen menschlichen Person, die weder durch staatliche Machtansprüche noch durch gesellschaftliche Abgrenzungsbedürfnisse in Frage zu stellen sind.

Die konstitutive Bedeutung des Menschenrechtsgedankens für das Begreifen des Rechts wie für den inneren Zusammenhang des Rechts mit seinen Begründungsprinzipien muß immer wieder neu ins $\mathrm{Be}-$ wußtsein gehoben werden. In vielen Teilen Europas ist dies derzeit 
vor allem im Blick auf die Tendenz notwendig, die Identität der eigenen Gesellschaft durch die Abgrenzung vom Fremden und durch die Ausgrenzung von Fremden zu sichern. All solche abgrenzenden Bemühungen um die eigene Identität finden an der Anerkennung der gleichen Würde und der gleichen Rechtsstellung jeder menschlichen Person ihre notwendige Grenze.

Jede Frage nach der inhaltlichen Begründung des Rechts führt unausweichlich auf die Frage nach dem Menschenbild des Rechts. Was es mit dem Bild des Menschen auf sich hat, kommt in der christlichen Tradition in besonderer Schärfe in der Lehre von der Rechtfertigung des Menschen durch Gottes Gnade im Glauben zum Ausdruck. Es war kein Zufall, daß Martin Luther der gewohnten philosophischen Definition, der Mensch sei ein Vernunitwesen, die theologische Definition entgegenstellte, der Mensch werde durch Glauben gerechtfertigt. Der Aussage „hominem esse animal rationale" trat damit die Aussage gegenüber: „hominem iustificari fide “5. Es ist freilich ein ungewöhnlicher Gedanke, diese Gegenüberstellung zum Ausgangspunkt einer rechtsethischen Überlegung zu machen.

\section{Das neue Interesse an Rechtfertigung}

Denn die Brisanz der von Luther formulierten Entgegensetzung blieb über lange Zeit verborgen. So wichtig die Lehre von der Rechtfertigung im Reformationszeitalter war und so sehr sie immer wieder als "protestantisches Prinzip“ beschworen wurde, so sehr galt diese Lehre doch über lange Zeit als eine theologische Spezialität, die nur für Eingeweihte verständlich sei. In kontroverstheologischer Betrachtung wurde sie lange Zeit als eine protestantische Sonderlehre betrachtet, deren Profilierung sich nur aus den konfessionellen Kontroversen der Reformationszeit erklären lasse. Inwieweit die Botschaft von der Rechtfertigung des Sünders das Ganze des christlichen Glaubens zu entschlüsseln vermag und inwieweit sie für das christliche Bild vom 
Menschen insgesamt zentral ist, wurde dagegen nur vergleichsweise selten erwogen. In einem verbreiteten Bewußtsein koppelte man diese Lehre exklusiv an die Martin Luther zugeschriebene Frage „Wie bekomme ich einen gnädigen Gott?" Mit der Diagnose, nicht mehr die Frage nach einem gnädigen Gott, sondern die Suche nach einem gnädigen Nächsten bestimme das moderne Bewußtsein, verband sich dann allzu schnell die Behauptung, damit habe auch das Rechtfertigungsthema seine Relevanz eingebüßt. Gegenüber der Gegenwartsbedeutung der Rechtfertigungslehre wurden deshalb insbesondere in der 2. Hälfte des 20. Jahrhunderts auch im Bereich von evangelischer Theologie und Kirche erhebliche Zweifel geäußert.

Doch plötzlich zog die theologische Lehre von der Rechtfertigung wieder Aufmerksamkeit auf sich. Sogar in manchen Tageszeitungen konnte man monatelang Berichte über ökumenische Einigungsversuche zu diesem Thema und über deren theologische Kritik lesen. Dasjenige Thema, das nach evangelischer Auffassung ,Mitte und Grenze reformatorischer Theologie“ bildet, ${ }^{6}$ wurde als ein ökumenisches Schlüsselthema erkannt. Mit der Unterzeichnung der Gemeinsamen Offiziellen Feststellung zur Rechtfertigungslehre am 31. Oktober 1999 in Augsburg kam dieser Vorgang zu einem gewissen Höhepunkt und Abschluß. ${ }^{7}$

Fast völlig unerwähnt blieb in all diesen Zusammenhängen, daß das Thema der Rechtfertigung erhebliche rechtsethische Konsequenzen hat. Der evangelische Theologe Karl Barth, den manche als einen protestantischen „Kirchenvater" des 20. Jahrhunderts bezeichnen, hat seinen eigenen Vorstoß in den Bereich der Rechtsethik unter die programmatische Überschrift „Rechtfertigung und Recht“ gestellt. ${ }^{8}$ Wenn inzwischen Rechtfertigung als ein ökumenisches Thema wiederent-

6 Vgl. E. Wolf, Die Rechtfertigungslehre als Mitte und Grenze reformatorischer Theologie, in: ders., Peregrinatio, Bd. II, München 1965, 11-21.

7 Die entscheidenden Texte sind beispielsweise in einer handlichen Ausgabe zusammengestellt von $P$. Lüning/R. Miggelbrink/H. J. Urban/J. Wanke (Hg.), Zum Thema: Gerechtfertigt durch Gott - Die gemeinsame lutherisch-katholische Erklärung, Paderborn 1999.

8 Ursprünglich 1938, abgedruckt in: K. Barth, Rechtfertigung und Recht. Christengemeinde und Bürgergemeinde, Zürich 1984. 
deckt worden ist und wenn sich ein neuer Sinn für die zentrale Bedeutung und Gegenwartsrelevanz der Rechtfertigungslehre entwickelt, dann kann auch der Versuch, den Zusammenhang von Rechtfertigung und Recht zu erschließen, aus einer konfessionellen Engführung befreit und als Beitrag zum ökumenischen Gespräch über Grundfragen der Rechtsethik gewürdigt werden.

Dabei ist freilich zu bedenken: Theologische Beiträge zur Ethik des Rechts sind heute alles andere als selbstverständlich. Sie werden von der Rechtswissenschaft und der Rechtsphilosophie in aller Regel auch nicht erwartet. Dabei braucht es jedoch nicht zu bleiben. Denn eine historische Besinnung zeigt schnell, daß unser Rechtssystem sich in beständiger Auseinandersetzung mit Grundeinsichten des christlichen Glaubens, insbesondere mit Grundaussagen des christlichen Menschenbildes, entwickelt hat. Diese Auseinandersetzung hat $\mathrm{zu}$ einem Menschenbild des Rechts geführt, nach welchem alle Menschen unbeschadet der Verschiedenheiten des Geschlechts, der Rasse, der Fähigkeiten, des Vermögens und sofort - als mit gleicher Würde begabt angesehen werden, weshalb ihnen allen die gleiche Achtung geschuldet ist. Die Radikalität dieses Menschenbilds des Rechts erschließt sich, so heißt meine These, am ehesten aus dem Gedanken der Rechtfertigung. Nicht nur unter historischen, sondern auch unter systematischen Gesichtspunkten ist deshalb der Beitrag der Theologie zur Ethik des Rechts von erheblicher Bedeutung. An keinem Thema erschließt sich das deutlicher als an der Verhältnisbestimmung von Rechtfertigung und Recht.

Ich will deshalb im folgenden zunächst die historischen Stufen skizzieren, auf denen der christliche Glaube das europäische Rechtsdenken beeinflußt hat (III.). Ich zeichne sodann die Debatte um die Rechtfertigungslehre in diese Entwicklung ein (IV.). Im Anschluß daran erörtere ich exemplarisch Karl Barths Versuch, den Zusammenhang von Rechtfertigung und Recht zu verdeutlichen (V.). Die Schwierigkeiten, die sich dabei zeigen, werden mich zu einer abschließenden Überlegung veranlassen (VI.). 


\section{Der Einfluß des christlichen Glaubens auf die europäische Rechtsentwicklung}

Der Weg, auf dem sich Impulse des christlichen Glaubens auf die westliche Rechtsentwicklung ausgewirkt haben, läßt sich grob in fünf Etappen einteilen. ${ }^{9}$

Am Beginn steht die Christianisierung des römischen Reichs. Während das Christentum in der Zeit der Christenverfolgungen zum Staat insgesamt wie zur Sphäre des Rechts in einer kritischen Distanz stand, beginnt mit der konstantinischen Wende zu Beginn des 4. Jahrhunderts und der offiziellen Anerkennung des Christentums als Reichsreligion durch Kaiser Theodosius gegen Ende desselben Jahrhunderts ein neuer Abschnitt. Rechtsinstitutionen, die von ihrer Herkunft her eng mit der römischen Staatsreligion verbunden waren, werden nun im Licht jüdischer und christlicher Moralvorstellungen verändert. Das läßt sich am deutlichsten an der Institution der Ehe zeigen, die nun als heterosexuelle, monogame und lebenslange Gemeinschaft konzipiert wird. Diese Prägung des Rechts durch Einflüsse des christlichen Glaubens wirkt sich umgekehrt auch in einer Verweltlichung des Christentums aus. Die Radikalität seiner Botschaft wird abgeschwächt; die prophetische Kritik sozialer Ungerechtigkeit und damit der Blick auf das Recht aus der Perspektive der Schwächeren treten in den Hintergrund.

Die zweite Etappe ist durch die Vorgänge gekennzeichnet, die Harold Berman zusammenfassend als die "päpstliche Revolution“ der Zeit zwischen 1050 und 1200 gekennzeichnet hat. ${ }^{10}$ In ihr vollzieht sich eine umfassende Systematisierung rechtlicher Regelungen; die Konkordanz der Bestimmungen in verschiedenen Rechtsbereichen entwikkelt sich zum entscheidenden Maßstab für das Recht. Im Decretum

9 Am Beispiel des Ehe- und Familienrechts hat John Witte, Jr. diese Etappen auf ähnliche Weise unterschieden; vgl. jetzt die zusammenfassende Darstellung in ders., From Sacrament to Contract. Marriage, Religion, and Law in the Western Tradition, Louisville/Kentucky 1997.

$10 \mathrm{H}$. J. Berman, Recht und Revolution. Die Bildung der westlichen Rechtstradition, Frankfurt a. M. 1991, $144 \mathrm{ff}$. 
Gratiani von 1140 wird dieser Grundsatz zum ersten Mal angewandt und zwar im Blick auf das kanonische Recht, also auf die innerkirchliche Rechtssphäre. Aber schon bald wird er auch auf andere Rechtsgebiete ausgedehnt. Mit dem Naturrecht wird zugleich diejenige Instanz benannt, welche die innere Konsistenz des Rechts verbürgen soll. Da die Prinzipien des Naturrechts sich zwar in der Offenbarung auffinden lassen, zugleich aber auch mit den Mitteln der Vernunft erkannt werden können, bedeutet dieser Schritt auf seine Weise eine Emanzipation von den unmittelbar biblischen Wurzeln westlichen Rechtsdenkens. Dessen Säkularisation setzt keineswegs erst mit dem Übergang zur Neuzeit ein. Sie ist vielmehr in der päpstlichen Revolution des 11. und 12. Jahrhunderts bereits angelegt und hat schon in der konstantinischen Wende des 4. Jahrhunderts ihre Vorgeschichte.

Folgenreich ist insbesondere das Bild der menschlichen Person, von dem sich das westliche Rechtsdenken von nun an leiten läßt. Sie wird als Individuum, genauer: als christliches Individuum konzipiert. Denn konstituiert wird die Person durch den Akt der Taufe. " Die Folgen, die sich aus diesem Personbegriff ergeben, sind keineswegs auf den kirchlichen Bereich beschränkt, sondern erstrecken sich auch auf das politische Gemeinwesen. An die Taufe heftet sich (in weiten Gebieten bis ins 19. Jahrhundert hinein) auch das Bürgerrecht; nach den schon im IV. Laterankonzil 1215 erlassenen Bestimmungen kann es nämlich nur von denen in Anspruch genommen werden, die mindestens einmal im Jahr, in der Osterzeit, beichten und die Heilige Kommunion empfangen. Wer daran nicht teilnehmen kann, also exkommuniziert ist, verliert damit nicht nur die Rechte der Kirchenmitgliedschaft, sondern auch das Bürgerrecht.

So sehr die päpstliche Revolution den Begriff der individuellen menschlichen Person ins Zentrum des Rechtssystems rückt, so weit ist sie doch von der Vorstellung allgemeiner Menschenrechte entfernt. Denn sie akzeptiert die Teilung der Kirche in zwei Gattungen von Christen - Kleriker und Laien - ; sie bestätigt die ständische Gliede-

11 „Baptismate homo constituitur in Ecclesia Christi persona” (CIC 1917 c. 87); vgl. H. Dombois, Das Recht der Gnade, Witten 1961, 309 f. 
rung der Gesellschaft; und sie begründet den Ausschluß der Nichtgetauften und der Exkommunizierten von den kirchlichen und damit auch von den bürgerlichen Rechten. Der Gedanke einer für alle Menschen gleichen Rechtsstellung kann deshalb noch nicht aufkommen. So trägt auch die Magna Charta Libertatum von 1215, die häufig als Vorläuferin der modernen Menschenrechtskataloge in Anspruch genommen wird, ${ }^{12}$ keineswegs den Charakter einer allgemeinen, sondern nur den einer ständischen Rechteerklärung. Sie kodifiziert diejenigen Rechte, welche die englischen Barone jener Zeit dem König Johann abgetrotzt hatten.

Eine dritte Etappe wird mit der Reformation erreicht. $\mathrm{Da}$ sie eine Verweltlichung der Wirklichkeitswahrnehmung bewirkte, gilt insbesondere für das Recht. Die Eigenständigkeit von weltlichen Rechtsverhältnissen wird unabhängig von kirchlichen Herrschaftsansprüchen anerkannt. Die Ehe wird von Luther ausdrücklich als ,weltlich Ding“ bezeichnet. Die weltlichen Stände werden dem geistlichen Stand gleichgestellt. Die Freiheit des Gewissens und der Religion wird als diejenige Grenzlinie anerkannt, an welcher die Herrschaftsansprüche der politischen Macht ein Ende finden sollen. In der Zeit der konfessionellen Kämpfe, die der Reformation folgen, setzt sich gegen immer wieder erneuerte Widerstände die Einsicht durch, daß die Rechtsstellung der menschlichen Person nur geachtet wird, wo ihre Gewissensfreiheit Anerkennung findet. Zusammen mit Impulsen des Renaissancehumanismus und der Spätscholastik bereitet die Reformation so eine Wende des Menschenbildes vor, die auf die Anerkennung der gleichen Würde aller Menschen drängt. Nun tritt der Gedanke ins Bewußtsein, daß alle Menschen über gleiche vorstaatliche Rechte - nämlich auf Leben, Freiheit und Eigentum - verfügen, die ihnen weder durch einen Gesellschaftsvertrag noch durch staatlichen Machtgebrauch entzogen werden können. Die Selbstbestimmung jeder menschlichen Person, die dadurch gesichert werden soll, betrifft insbesondere auch

12 So wird ihr Text beispielsweise wiedergegeben in W. Heidelmeyer (Hg.), Die Menschenrechte, Paderborn 1972, 47 ff. 
den religiösen Bereich. Insofern steht die Religionsfreiheit von Anfang an im Zentrum des neuzeitlichen Menschenrechtsdenkens.

Die konfessionellen Kämpfe der nachreformatorischen Ära leiten zur vierten Etappe des hier beschriebenen Weges über. Die Tatsache, daß der Streit um die Wahrheit des Glaubens nicht nur Zwietracht, sondern auch blutige Kriege zur Folge hat, führt zu der Überzeugung, daß die Rechtsordnung des Staates auf andere Fundamente aufgebaut sein $\mathrm{mu} ß$ als diejenigen der Religion. Diese Wende kommt in der Statskonstruktion des Hobbes'schen Leviathan ebenso zum Ausdruck wie in der berühmten These des Hugo Grotius, daß eine Rechtsordnung Bestand haben müsse, auch wenn wir annähmen, daß es Gott nicht gäbe (etsi Deus non daretur). ${ }^{13}$ Nun wird der Staat selbst zur Quelle des Rechts; das Zeitalter des Positivismus kündigt sich an. Diese Etappe läßt sich als eine Zeit der Verstaatlichung des Rechts bezeichnen. Sie provoziert die Forderung nach Gegengewichten, die der Ausdehnung staatlicher Gewalt Einhalt gebieten sollen. Solche Gegengewichte sieht man in den Menschen- und Bürgerrechten, die im Zuge der amerikanischen und französischen Revolutionen zum ersten Mal feierlich kodifiziert werden.

In der Epoche der Aufklärung, der wir die ersten modernen Menschenrechtskataloge verdanken, werden zugleich die Voraussetzungen für die fünfte Etappe geschaffen, auf der sich biblisches Rechtsdenken in modernes Rechtsbewußtsein transformiert. Sie liegen in der Neuentdeckung der menschlichen Subjekthaftigkeit und Autonomie. Die Unabhängigkeit der menschlichen Selbstbestimmung von allen göttlichen wie weltlichen - Verfügungsansprüchen ist das entscheidende Postulat der Aufklärung. Daß alle Geltungsansprüche in der Vernunft des menschlichen Subjekts jeweils neu hervorgebracht werden müssen, bildet die entscheidende Folgerung. Dieser Gedanke - so ambivalent seine Voraussetzungen wie seine Auswirkungen auch sein mögen - trägt maßgeblich dazu bei, die menschliche Person in ihrer Rechtssubjektivität als entscheidenden Bezugspunkt des Rechtsdenkens anzuerkennen. Doch in die Verfassungen vieler Nationalstaaten 
findet dieser Gedanke nur sehr zögernd Eingang. Und es dauert mehr als eineinhalb Jahrhunderte, bis er mit der Allgemeinen Erklärung der Menschenrechte von $1948 \mathrm{zu}$ einem entscheidenden Baustein des internationalen Rechts wird.

Befinden wir uns heute an der Schwelle zu einer sechsten Etappe der Begegnung zwischen biblischem Rechtsdenken und westlichem Rechtssystem? Zwei Beobachtungen deuten darauf hin.

Zum einen zeigt sich an vielen Indizien, daß der Proze $\beta$ neuzeitlicher Subjektivierung und Individualisierung an eine Grenze-stëßt, die nur mit selbstzerstörerischen Folgen überschritten werden kann. Eine Neuorientierung, die es wagt, über das Gemeinwohl, die Gemeinschaft, die Umwelt und eine lebensfähige Zukunft nachzudenken, erscheint als unausweichlich. In neuer Form stellt sich die Frage nach der Zusammengehörigkeit von Individualität und Sozialität im Verständnis des Menschen. Gefragt wird wieder nach einer Anerkennung der menschlichen Subjektivität, welche die Bejahung verpflichtender Gemeinschaften nicht aus-, sondern einschließt. Gesucht wird nach einem Begriff menschlicher Selbstentfaltung, der die Bewahrung der Bedingungen des gemeinschaftlichen Lebens in Natur und Gesellschaft einbegreift, sowie nach einem Begriff menschlicher Freiheit, der die Verantwortung für andere als Ausdruck eben dieser Freiheit zu verstehen lehrt. Was heute ansteht, ist eine neue Verknüpfung liberaler mit kommunitaristischen Traditionen. Die unter diesen Namen in der neueren Gesellschaftstheorie gegeneinander gewendeten Konzeptionen waren freilich - vor allem dank biblischer Impulse - im westlichen Rechtsdenken, insbesondere in dem ihm zu Grunde liegenden Begriff der Gerechtigkeit, immer verknüpft. Denn Gerechtigkeit zielt nicht nur darauf, daß jeder sein Recht erhält, sondern daß dem andern Recht widerfährt und daß die Gemeinschaft sich unter Bedingungen gleicher Freiheit für alle zu entfalten vermag. In der Weiterentwicklung des Rechtsdenkens, welche die Entgegensetzung von liberalen und kommunitaristischen Konzeptionen hinter sich läßt, kann biblischen Rechtsvorstellungen eine wichtige Bedeutung zukommen.

Zum andern befinden wir uns vor der Aufgabe, ein weltumspannendes Rechtsbewußtsein zu entwickeln, das seine Geltungsgrundlage in 
Prinzipien eines planetarischen Ethos hat. Die Aufgabe, die Lebensfähigkeit des Planeten Erde zu erhalten und menschenwürdige Lebensbedingungen $\mathrm{zu}$ sichern, erfordert eine Zusammenarbeit über die Grenzen kultureller Traditionen und religiöser Überzeugungen hinweg. Das westliche Rechtsdenken hat sich den Zugang zu dieser Aufgabe gerade dadurch versperrt, daß es für die religiöse Dimension des Rechts weithin blind geworden ist. Denn eben deshalb steht es der Verknüpfung von Recht und Religion in anderen Traditionen oft verständnislos gegenüber. Insbesondere die europäische Debatte neigt dazu, alle Verknüpfungen zwischen religiösen Traditionen und aktuellem Recht im Sinn einer Identifikation zu deuten und mit dem Vorwurf des Fundamentalismus zu belegen. Nicht nur in der christlichen, sondern ebenso in der jüdischen und in der islamischen Tradition ist der Fundamentalismus jedoch keineswegs die einzige Form, religiöse Überzeugungen in ihrer begründenden Bedeutung für die Ordnung des Rechts und die Gestaltung der Gesellschaft zur Geltung zu bringen. Gerade wer den Gefahren des Fundamentalismus entgegentreten will, ist deshalb gut beraten, den differenzierteren Formen, in denen der Zusammenhang von Recht und Religion gedeutet worden ist, Aufmerksamkeit zu schenken.

Verkürzend ist es auch, wenn jede Verknüpfung zwischen dem Recht und religiösen Traditionen in partikularistischem Sinn gedeutet wird. Das geschieht beispielsweise, wenn eine neue Diskussion über den eurozentrischen Charakter des westlichen Rechtssystems und insbesondere der Menschenrechte aufbricht, von denen behauptet wird, sie könnten in kulturell und religiös anders geprägten Regionen der Erde nicht heimisch werden. Die Behauptung, die Menschenrechte seien exklusiv an einen europäischen und amerikanischen Verständigungszusammenhang gebunden, findet sich vorzugsweise bei Autoren, die diesen Verständigungszusammenhang selbst nur noch in verstümmelter Form zur Kenntnis nehmen. Sie lassen nämlich die Bedeutung von Judentum und Christentum, ja aller Religion, außer Betracht. Sie verkennen, daß Religion keineswegs nur partikularisierende, sondern ebenso auch universalisierende Wirkungen entfaltet. Denn sie bezieht die Wirklichkeit des Menschen auf den umfassenden Horizont einer 
göttlichen Wirklichkeit; sie deutet also den Ort des Menschen im Horizont des "Ganzen“. Die Konkurrenz zwischen den großen Weltreligionen darf nicht den Blick darauf verstellen, daß der religiöse Deutungshorizont gerade nicht partikularistisch verengenden, sondern universalistiscb verallgemeinernden Charakter trägt.

Wer zur Entwicklung eines weltumspannenden Rechtsbewußtseins beitragen will, sieht sich insofern keineswegs dazu genötigt, die Verknüpfungen zwischen Recht und Religion abzustreifen. Eine Vernachlässigung dieses Faktors erschwert vielmehr auch praktisch die Verständigung zwischen den unterschiedlichen Rechtskulturen, die um eines weltumspannenden Rechtsbewußtseins willen dringend erforderlich ist. Die Gleichgültigkeit gegenüber der religiösen Dimension des Rechts vertieft nämlich unweigerlich die Kluft zwischen westlichen und nichtwestlichen Rechtsauffassungen. Sie kann unter Umständen westlichen Gesprächspartnern jeden Zugang zu dem inneren Zusammenhang von Recht und Religion versperren, der insbesondere dort noch große Bedeutung hat, wo Islam, Buddhismus, Hinduismus oder Konfuzianismus das öffentliche Bewußtsein prägen. Wer fragen will, wie der Gedanke der Menschenrechte in diesen Kulturen heimisch werden kann, muß auch in der eigenen Kultur wieder nach der verschütteten Verbindung von Recht und Religion fragen.

\section{Rechtfertigung - was ist das?}

Diese Verbindung, so heißt die Hauptthese meiner Überlegungen, läßt sich exemplarisch am Verhältnis von Rechtfertigung und Recht verdeutlichen. Ihm wenden wir uns nun zu.

Das Wort „Rechtfertigung“ ist in der Sprache des Rechts zu Hause. Aber es gehört zu den archaischen Worten der Rechtssprache. Wir Heutigen kennen es am ehesten noch in seinem reflexiven Gebrauch. „Man rechtfertigt sich“ gegen einen Vorwurf oder eine Anklage; aus der Position des Angegriffenen heraus sucht man sich ins rechte Licht zu rücken. Das „sich rechtfertigen“ steht insofern an der Stelle, an der 
in der älteren Rechtssprache die Rede davon war, daß man seine Unschuld anzeige oder sich entschuldige.

Die moderne Weise, von Rechtfertigung zu sprechen, hat es mit der Frage zu tun, wem eine Handlung zugerechnet wird und wie der Betreffende diese Handlung zu ,rechtfertigen“ vermag. In der neuzeitlichen Entwicklung ist diese Rechtfertigungsfrage in drei Hauptschüben zur Sprache gekommen: als Theodizee, als Anthropodizee und als Soziodizee. ${ }^{14}$ Die „Theodizee“ fragte danach, inwiefern Gott als Urheber des - physischen, moralischen oder metaphysischen - Übels in der Welt anzusehen sei und wie er sich für dieses Übel rechtfertigen könne. Die nach der anthropologischen Wende der Aufklärung aufkommende „Anthropodizee“ fragte danach, inwiefern der als frei und autonom verstandene Mensch für das Böse in der Welt verantwortlich gemacht werden müsse und wie er sich dafür rechtfertigen könne. Die gesellschaftstheoretische Wende des 19. und 20. Jahrhunderts suchte die Ursachen für das gesellschaftliche Übel in der Gesellschaft selbst und führte damit zu einer "Soziodizee“; sie fragte, inwieweit die Gesellschaft für das Böse, das den Menschen widerfährt, verantwortlich sei und wie sie sich dafür rechtfertigen könne.

Ursprünglich jedoch bezog sich die Frage nach der Rechtfertigung gar nicht auf die Rechtfertigung von Handlungen, sondern auf die Rechtfertigung von Personen. Die alles entscheidende Überzeugung hieß, daß ein Mensch sich weder für seine Handlungen noch durch seine Handlungen rechtfertigen könne. Jede derartige Form der Selbstzentrierung führe vielmehr an der Möglichkeit der Rechtfertigung überhaupt vorbei; sie führe nur in das Gericht nach den Werken, vor welchem kein Mensch bestehen könne. Rechtfertigung könne dagegen nur erlangen, wer sich an die Gerechtigkeit hält, die vor Gott gilt und auch von ihm allein herbeigeführt wird. Von Rechtfertigung also ist dort die Rede, wo es nicht nur um die Handlungen, sondern um die Person selbst geht - um die Person des Menschen in ihrem Gegenüber zu Gott.

14 Vgl. W. Huber, Theodizee, in: E. Rudolph/E. Stöve (Hg.), Geschichtsbewußtsein und Rationalität. Zum Problem der Geschichtlichkeit in der Theoriebildung, Stuttgart 1982,371-406. 
$\mathrm{Da}$ es um die Person selbst geht, klingt auch im ursprünglichen rechtlichen Gebrauch des Wortes „rechtfertigen“ an. Die deutschen Gerichtsordnungen des späten Mittelalters und der frühen Neuzeit benutzten das Wort, um das Ausfertigen eines Urteils und das Vollstrecken des Rechts an einem Missetäter zu bezeichnen. War von einer „scharfen Rechtfertigung“ die Rede, so war die Folter gemeint; sprach man von einer „peinlichen Rechtfertigung“, so meinte man damit die Hinrichtung durch den Henker. ${ }^{15}$

Man muß diesen dunklen Klang mithören, wenn man die epochale Bedeutung verstehen will, die der Begriff der Rechtfertigung mit der Reformation erlangt hat. Stellvertretend für die vielen, die schuldig geworden sind, nimmt Christus als der allein Schuldlose im Kreuzestod das Furchtbare einer ,peinlichen Rechtfertigung“ auf sich und vermittelt den vielen, die der Macht der Sünde unterworfen sind, die Rechtfertigung, indem er sie ihnen zugleich erspart. Denn der Tod, den er erleidet, wird zur Sühne für die Schuld der vielen; er vollzieht sich ein für allemal, so daß niemals mehr ein Sühnopfer für die Schuld der Menschen erbracht werden muß. Der tod-ernste Bezug, der auf seine Weise schon mit der Sühnopfertheologie des Paulus angebahnt ist, klingt in der Rechtfertigungslehre der Reformation immer mit; sie ist kreuzestheologisch konzipiert.

Nur ein ferner Nachklang davon ist in den lexikalischen Definitionen des Begriffs der Rechtfertigung wahrzunehmen. Ich greife ein zufälliges Beispiel heraus: „Rechtfertigung, in der evangelischen Theologie die Grundlehre der Reformatoren, die Lehre von der Rechtfertigung allein aus dem Glauben auf Grund von Römerbrief $3 .^{16}$ Danach vermag der Mensch von sich aus, trotz Bemühen um ,gute Werke' und

15 Vgl. W. Elert, Deutschrechtliche Züge in Luthers Rechtfertigungslehre, in: M. Keller-Hüschemeyer (Hg.), Ein Lehrer der Kirche, Berlin-Hamburg 1967, 23-31; vgl. O. H. Pesch/A. Peters, Einführung in die Lehre von Gnade und Rechtfertigung, Darmstadt 1981, 135.

16 Gemeint sind die Schlüsselaussagen von $\mathrm{Rm} \mathrm{3,} \mathrm{22ff.,} \mathrm{28:} \mathrm{„Denn} \mathrm{es} \mathrm{ist} \mathrm{hier} \mathrm{kein}$ Unterschied: sie sind allesamt Sünder und ermangeln des Ruhmes, den sie bei Gott haben sollten, und werden ohne Verdienst gerecht aus seiner Gnade durch die Erlösung, die durch Christus Jesus geschehen ist. ... So halten wir nun dafür, daß der Mensch gerecht wird ohne des Gesetzes Werke, allein durch den Glauben." 
,Verdienste', nichts, um das durch die Sünde gestörte Verhältnis zu Gott wiederherzustellen. Eine Änderung tritt nur dadurch ein, daß Gott aus reiner Gnade sich dem Menschen wieder zuwendet, d.h. ihn rechtfertigt. Der Mensch ist lediglich empfangend dabei; in dem ihm von Gott aus freier Güte geschenkten Glauben nimmt er Gnade und Rechtfertigung an. Nach katholischer Lehre verläuft die Rechtfertigung des Sünders von seiten des Menschen in einem durch Gottes Gnade eingeleiteten sittlichen Prozeß, auf Grund dessen dann Gott ihm die heiligmachende Gnade aus freier Güte schenkt und zugleich die Sünden vergibt. Erst dann kann der Mensch verdienstlich gute Werke verrichten."17

Eine solche lexikalische Definition spricht heute nur relativ wenige Menschen unmittelbar an. Insofern überrascht es nicht, daß vielen heutigen Zeitgenossen der religiöse Sinn dessen, was mit Rechtfertigung gemeint sein kann, sehr fern gerückt ist. Überraschender war schon die vergleichsweise lebhafte Debatte über die theologische Lehre von der Rechtfertigung, die in den letzten Jahren in Gang gekommen ist. Ausgelöst wurde sie, wie bereits erwähnt, durch den Versuch der römisch-katholischen Kirche und des Lutherischen Weltbunds, zu gemeinsamen Aussagen über diese Lehre zu kommen, an der sich im 16. Jahrhundert die Konfessionsspaltung entzündet hatte.

Diese Bemühungen mündeten schließlich in die Unterzeichnung eines gemeinsamen lutherisch-katholischen Dokuments zur Rechtfertigungslehre am 31. Oktober 1999 in Augsburg. Datum wie Ort waren in gleicher Weise symbolisch gewählt. Denn der 31. Oktober ist der Reformationstag, an dem nach alter Überlieferung Martin Luther im Jahr 1517 seine 95 Thesen zu Ablaß und Buße an die Tür der Schloßkirche zu Wittenberg nagelte; damit, so sagt es das herrschende Geschichtsbild, begann die Konfessionsspaltung, die gerade für ein Land wie Deutschland in besonderer Weise zum Schicksal werden sollte. Insofern ist der 31. Oktober ein Schicksalstag. Augsburg aber ist der Ort, an dem im Jahr 1530 ein Reichstag zusammentrat, um angesichts der durch Luther ausgelösten Auseinandersetzungen eine gütliche

17 Der Neue Brockhaus, Bd. 3, Leipzig 1941, 665. 
Einigung zu versuchen. Doch das Bekenntnis, das die evangelischen Reichsstände dem Reichstag vorlegten - eben das „Augsburgische Bekenntnis" - führte keineswegs zur Einigung, sondern wurde schließlich zu einem Dokument der Spaltung, nämlich zum grundlegenden Bekenntnisdokument der evangelischen Seite.

An diesem bewußt gewählten Ort und zu diesem so wohl bedachten Datum also unterzeichneten Vertreter der römisch-katholischen Kirche und des Lutherischen Weltbunds jenes Dokument, demzufolge beide Kirchen in Grundwahrheiten der Rechtfertigungslehre übereinstimmen, so daß die Lehrverurteilungen, durch die man sich im Reformationsjahrhundert voneinander abgrenzte, ihre kirchentrennende Bedeutung verloren haben.

Durch diesen Vorgang und die öffentliche Diskussion, die er insbesondere in Deutschland nach sich zog, ist die Rechtfertigungslehre in ihrer Gegenwartsbedeutung neu ins Bewußtsein getreten. Sie kann nicht länger als eine evangelische Sonderlehre betrachtet werden; für Katholiken wie für Protestanten kommt in ihr der Kern des christlichen Glaubens zum Ausdruck.

In dieser Einsicht sehe ich eine der positivsten Auswirkungen der ökumenischen Debatte während der letzten Jahre. Ich sage das mit besonderer Freude in Würzburg, wo unter der bestimmenden Mitwirkung des hiesigen katholischen Bischofs Paul-Werner Scheele entscheidende Vorbereitungen für die schließlich glücklich zustande gekommene Verständigung getroffen wurden. Die entscheidenden Entwürfe für die „Gemeinsame Erklärung zur Rechtfertigung“ sind nach der Stadt Würzburg benannt: „Würzburg I“ kam 1996, „Würzburg II" 1997 zustande. $^{18}$ Es gibt also keinen geeigneteren Ort, um den erreichten Diskussionsstand zu würdigen und eine erneute Verhältnisbestimmung von Rechtfertigung und Recht $\mathrm{zu}$ versuchen als Würzburg.

18 Vgl. die knappe Darstellung bei $H$. Wagner, Die Rechtfertigungsproblematik im ökumenischen Dialog. Vom Malta-Papier bis zur Gemeinsamen Erklärung, in: B. J. Hilberath/W. Pannenberg (Hg.), Zur Zukunft der Ökumene. Die „Gemeinsame Erklärung zur Rechtfertigungslehre", Regensburg 1999, 58-69. 
Die Frage, wie der sündige Mensch von Gott angenommen wird und vor ihm Anerkennung findet, bildete den Kern des Konflikts, der unter dem Namen „Rechtfertigungslehre“ im Reformationsjahrhundert entbrannte und schließlich zur Trennung der reformatorischen Kirchen von der römisch-katholischen Kirche führte. Luthers Antwort im Anschluß an den Apostel Paulus lautete: „allein aus Gnade“ und ,allein im Glauben" um Christi willen. Luther gelangte zu dieser Einsicht durch ein neues Verständnis von Schlüsselaussagen des paulinischen Römerbriefs. Wahrscheinlich gewann er diese Erkenntnis bereits in der Zeit der Vorlesungen über die Psalmen 1513/15 oder über den Römerbrief 1515/16. Unklarheiten der Datierung erklären sich daraus, daß Luther selbst in einem späten Selbstzeugnis die reformatorische Entdeckung erst auf das Jahr 1519 datiert, also auf die Zeit nach dem Thesenanschlag. Jedoch spricht schon der Inhalt der Römerbriefvorlesung selbst dafür, daß die entscheidende Entdeckung - das „Turmerlebnis" - auf die Zeit dieser Vorlesung zu datieren ist.

„Mit außerordentlicher Leidenschaft“ - so berichtet Luther rückblickend im Jahr 1545 - „war ich davon ergriffen, Paulus im Brief an die Römer kennenzulernen; aber es hatte bis dahin im Wege gestanden nicht die Kälte meines Herzens, sondern das einzige Wort im ersten Kapitel (des Römerbriefs): ,Die Gerechtigkeit Gottes wird im Evangelium offenbart.' Denn ich haßte dieses Wort ,Gerechtigkeit Gottes', welches ich nach der üblichen Gewohnheit aller Doktoren gelehrt worden war, philosophisch von der sogenannten formalen oder aktiven Gerechtigkeit zu verstehen, durch die Gott gerecht ist und die Sünder und Ungerechten straft. Ich konnte den gerechten, die Sünder strafenden Gott nicht lieben, im Gegenteil, ich haßte ihn sogar. Obwohl ich als Mönch untadelig lebte, fühlte ich mich vor Gott doch als Sünder, und mein Gewissen quälte mich sehr. Ich wagte nicht zu hoffen, daß ich Gott durch meine Genugtuung versöhnen könnte. Ich war unmutig gegen Gott, wenn nicht mit heimlicher Lästerung, so doch mit gewaltigem Murren, indem ich sprach: Muß Gott durch das Evangelium Leid auf Leid fügen und uns auch durch das Evangelium seine Gerechtigkeit und seinen Zorn androhen? So raste ich in meinem verwirrten Gewissen, pochte aber trotzdem ungestüm an dieser Stelle 
bei Paulus an, indem ich vor Durst brannte zu wissen, was der heilige Paulus wollte. Da erbarmte Gott sich meiner. Unablässig sann ich Tag und Nacht, bis ich endlich den Zusammenhang der Worte beachtete, nämlich: ,Die Gerechtigkeit Gottes wird im Evangelium offenbart, wie geschrieben steht: Der Gerechte lebt aus dem Glauben.' Da begann ich die Gerechtigkeit Gottes als diejenige zu verstehen, durch welche der Gerechte als durch Gottes Geschenk lebt, nämlich aus dem Glauben. Ich fing an zu begreifen, daß dies der Sinn sei: durch das Evangelium wird die Gerechtigkeit Gottes offenbart, nämlich die passive, durch welche uns der barmherzige Gott durch den Glauben rechtfertigt, wie geschrieben steht: ,Der Gerechte lebt aus dem Glauben.' Da fühlte ich mich wie ganz und gar neu geboren, und durch offene Tore trat ich ins Paradies selbst ein. Gleich zeigte mir die ganze heilige Schrift ein völlig anderes Gesicht. ... Mit so großem Haß, wie ich zuvor das Wort, Gerechtigkeit Gottes' gehaßt hatte, mit so großer Liebe hielt ich jetzt dies Wort als das allerliebste hoch. So wurde für mich diese Stelle des Paulus zur Pforte ins Paradies. “19

Ungefähr drei Jahrzehnte nach dem geschilderten Geschehen geschrieben, klingen Luthers Zeilen wider von der bebenden Erregung, die jene Entdeckung bei ihm auslöste. Aber besonders erstaunlich ist, daß diese Entdeckung, die sich als ein Ereignis von weltgeschichtlicher Dimension erweisen sollte, auf eine philologische Feststellung zurückgeht. Die Reformation beginnt nämlich mit einem Auslegungsproblem. Dadurch, daß eine Aussage des Apostels Paulus neu verstanden wird, verändert sich bei Luther das Koordinatensystem. Seit er weiß, was Paulus in seinem Römerbrief unter „Gerechtigkeit Gottes" versteht, gewinnt er Klarheit über seine Theologie. Aber auch ein persönliches Glaubensproblem ist für ihn dadurch gelöst.

Mit plötzlicher Wucht überkam Luther die Einsicht, daß Gottes Gerechtigkeit in Wahrheit etwas ist, das Gott dem Sünder schenkt. Umstürzend neu war die Erkenntnis, daß Gott gerade darin gerecht ist, $\mathrm{da} \beta$ er dem Menschen seine Gerechtigkeit zueignet und ihn damit bekleidet, indem er ihn rechtfertigt. Die existentielle Erfahrung also

19 M. Luther, Vorrede zum Band I der Opera Latina (1545) (Studienausgabe 5, $635 \mathrm{ff}$.). 
bestand in der Begegnung mit dem barmherzigen, rechtfertigenden Gott.

Die theologische Erkenntnis aber hatte ihren Kern darin, daß eine lange Tradition die Gerechtigkeit Gottes deshalb mißverstanden hatte, weil sie in ihr bloß eine Eigenschaft, nicht aber eine Gabe Gottes hatte sehen können. Luther entdeckte parallele Sprachformen im Hebräischen. Wo von der Weisheit Gottes, seiner Kraft, seinem Heil die Rede ist, da ist jeweils nicht nur eine Eigenschaft Gottes, sondern die Gabe gemeint, durch die er uns weise und stark macht oder in einen heilsamen Zustand versetzt. All diese Wortverbindungen sind also kausativ zu deuten: sie bezeichnen das, was Gott an den Menschen und für sie bewirkt. Damit aber wird auch die Stellung der Menschen vor Gott grundstürzend verändert. Sie wird durch das bestimmt, was sie von Gott empfangen, nicht etwa durch das, was sie vor Gott darstellen oder zuwege bringen. Für kein Thema ist das wichtiger als für die Gerechtigkeit, die vor Gott gilt. Sie ergibt sich nicht aus menschlichen Leistungen, sondern aus göttlicher Gnade. Kurzum: Das Gottesbild und die Vorstellung von der Beziehung zwischen Gott und Mensch verändern sich tiefgreifend.

Weil diese Beziehung allein in der Gnade Gottes gründet, kann sie auch nur im Glauben ergriffen werden. Allerdings darf auch dieser Glaube dann nicht als ein menschliches Werk verstanden werden; vielmehr ist er diejenige Vereinigung mit Christus, durch welche die göttliche Gnade empfangen wird. Auch der Glaube ist ein Geschenk, nicht eine selbstmächtige menschliche Aktion. „Rechtfertigung aufgrund der Gnade durch den Glauben“" - so läßt sich Luthers Auffassung am kürzesten zusammenfassen.

Die Gerechtigkeit, die Gott so dem Menschen zueignet, bleibt eine für ihn fremde Gerechtigkeit. Von sich aus kann er sein Sündersein weder verändern noch überwinden. Das hat Luther zu der paradoxen Aussage veranlaßt, der Christ sei ,gerecht und Sünder zugleich“. In der Zeit seiner reformatorischen Entdeckung hat er das einmal so erläutert:

„Denn solange die Heiligen immer ihre Sünde vor Augen haben und ihre Gerechtigkeit von Gott gemäß seiner Barmherzigkeit erflehen, werden sie immer ohne weiteres auch von Gott gerechtgesprochen. 
Dennoch sind sie von sich aus gesehen selbst und in Wahrheit ungerecht, von Gott aus aber, der sie wegen dieses Bekenntnisses der Sünde anerkennt, gerecht; in Wahrheit Sünder, aber im Urteil des barmherzigen Gottes gerecht; gerecht, ohne es zu wissen, und wissentlich ungerecht; Sünder in ihrem Tun, Gerechte aber in der Hoffnung. “20 $\mathrm{Zu}$ den wichtigen Folgerungen aus dieser Einsicht gehörte es, daß Luther und deutlicher noch sein Mitkämpfer Melanchthon zwischen der Gerechtsprechung und der Gerechtmachung des Menschen unterschieden. Denn bedeutungslos wurden die Werke des Menschen auch in Luthers Betrachtungsweise nicht. Doch trugen sie zur Gerechtsprechung des Menschen vor Gott nichts bei. Sie gehörten für ihn vielmehr in den Vorgang der Gerechtmachung, der Heiligung oder Erneuerung des Menschen. Luther kannte die ,guten Werke“, ja er hielt sogar große Stücke auf sie. Aber sie folgten auf das Geschenk der göttlichen $\mathrm{Ge}-$ rechtigkeit, sie gingen ihm nicht als Vorbedingung voraus. ${ }^{21}$

Ohne Zweifel hat Luther mit der Neuentdeckung der Rechtfertigung allein aufgrund der Gnade und allein durch Glauben eine Tradition begründet; der Weg dazu war die Traditionskritik. Seine eigene Lebenssituation führte dazu, daß er sich mit den gewohnten Deutungen der "Gerechtigkeit Gottes“ nicht abfand, sondern weiterfragte. Nach langem Suchen erschloß sich ihm der Sinn der paulinischen Redeweise neu. Was er bei Paulus wieder entdeckte, war zwar auch manchen Theologen vor ihm nicht unbekannt gewesen. Aber niemand hatte diese Einsicht so konsequent mit der einen grundlegenden Formulie-

20 M. Luther, Römerbriefvorlesung 1513-15 (Weimarer Ausgabe 56, 272).

21 Insofern bleibt es in reformatorischer Ethik nach meiner Überzeugung dabei, daß menschliches Handeln in Gottes Geschenk an den Menschen, nämlich dem Geschenk seiner rechtfertigenden Gnade, gründet. Der Einwand von Hans G. Ulrich gegen einen solchen Ansatz überzeugt mich insofern nicht. Es erscheint mir auch als nicht überzeugend, diesem rechtfertigungstheologisch begründeten Ansatz der Ethik einen anderen Ansatz entgegenzusetzen, in welchem es die Aufgabe christlicher Ethik ist, die Gegenwärtigkeit des göttlichen Tuns im menschlichen Leben zu beschreiben. Hilfreicher wäre es, sich an der Kategorie des darstellenden Handelns sowie daran zu erinnern, daß der christliche Gottesdienst die Aufgabe hat, die Gegenwärtigkeit Gottes in unserer Welt zur Darstellung zu bringen. Doch mit dem Gesamtproblem der Ethik sollte dies nicht gleichgesetzt werden. Vgl. H. G. Ulrich, Rechtfertigung und Ethik, in: Berliner Theologische Zeitschrift 17, 2000, 48-64. 
rung im ersten Kapitel des Römerbriefs verbunden. Und vor allem: Niemand hatte mit solcher Konsequenz wie Luther gesehen, wie das Geschenk der Gerechtigkeit Gottes und das Heil der Menschen zusammenhängen.

Gewehrt war mit dieser Neuentdeckung der Vorstellung, der Mensch könne durch eigene gute Werke an seiner Rechtfertigung beteiligt sein oder er könne sich durch den Erwerb eines Ablasses einen Nachlaß seiner Sündenstrafen erwirken. Dem wiederum widersprach das Konzil von Trient unter vier Gesichtspunkten: Es verwarf ausdrücklich die Ablehnung jeder Mitwirkung des Menschen bei seiner Rechtfertigung; folgerichtigerweise bestritt es die These der Reformatoren, daß die Rechtfertigung ,allein durch den Glauben“ empfangen werde; es beharrte gegen die Reformatoren darauf, daß Glaube und Liebe auch eine Wirklichkeit im Menschen selbst seien; und es bestritt schließlich, daß die Heilsgewißheit allein im Glauben gründen könne. ${ }^{22}$

Man hat Luthers Grundfrage im nachhinein auf die verkürzende Formel gebracht: „Wie kriege ich einen gnädigen Gott?" Verkürzend ist das, weil in einer solchen Formulierung ein Heilsegoismus steckt, der Luthers Intention nicht trifft. Man hat diese Formel gleichwohl benutzt, um mit ihrer Hilfe die Behauptung zu stützen, die reformatorische Frage sei nicht mehr die Frage des modernen Menschen. Mit der anthropologischen Wende der Neuzeit datiert man dann den Abschied von Luthers Fragestellung. Nicht mehr die Freiheit, die aus der Bindung des Gewissens an Gottes Wort ihre Kraft bezieht, sondern diejenige, die sich der menschlichen Autonomie verdankt, tritt ins Zentrum. Seit der Aufklärung beherrscht nicht mehr die Frage nach dem gnädigen Gott, sondern nach dem seiner selbst bewußten Menschen das Feld. Nicht mehr die Theodizee, sondern die Anthropodizee steht im Mittelpunkt. Gefragt wird nicht mehr, was Gott in seiner Welt zuläßt, sondern wozu der Mensch in seiner Welt fähig ist.

Ohne Zweifel sind die zwei Jahrhunderte zwischen dem Ende des achtzehnten und dem Ende des zwanzigsten Jahrhunderts durch eine

22 Vgl. O. H. Pesch/A. Peters, Einführung in die Lehre von Gnade und Rechtfertigung, Darmstadt 1981, 33 ff. 
eigentümliche Anthropozentrik geprägt. Deren Spannung zu Luthers Theozentrik ist nicht zu übersehen. Aber beim Übergang zum 21. Jahrhundert meldet sich auch die Frage an, ob dieser Anthropozentrik wirklich das letzte Wort gebührt. Zwar geben die anhaltenden Fortschritte von Wissenschaft und Technik dem menschlichen Selbstbewußtsein immer wieder neue Nahrung; doch zugleich meldet sich ein neues Verständnis für die Einbettung menschlichen Lebens in den umgreifenden Zusammenhang der Natur. Zwar herrscht gerade in hoch entwickelten Industriegesellschaften noch immer eine Vorstellung vor, nach welcher der Mensch sein Leben selbst in die Hand nehmen und den Sinn seines Lebens selbst verwirklichen müsse; doch zugleich zeigt sich ein neues Suchen nach Transzendenz und einem Sinn des Lebens, den der Mensch nicht selbst hervorbringt. Zwar haben sich die Spielräume menschlichen Handelns und die Reichweite menschlicher Macht dank neuer technischer Möglichkeiten in unvorhersehbarer Weise erweitert; doch hat sich dabei auch die Verführbarkeit des handelnden Menschen und die Ambivalenz menschlichen Machtgebrauchs auf unvorhersehbare Weise gezeigt. Das zwanzigste Jahrhundert hat nicht nur ungeahnte Fortschritte, sondern auch unvorstellbare Verbrechen hervorgebracht. So zeigt sich im Rückblick auf dieses Jahrhundert, daß der Mensch ein Wesen bleibt, das sich nicht selbst zu rechtfertigen vermag. So viel dem Menschen auch möglich ist - Bestand erhält sein Leben nicht durch das, wozu er selbst fähig ist. Ein halbes Jahrtausend nach Luthers reformatorischer Entdeckung gewinnt seine Einsicht, daß der Mensch mehr ist, als er selbst aus sich macht, neues Gewicht.

Die Aktualität der reformatorischen Entdeckung macht verständlich, warum die Rechtfertigung aufgrund der Gnade durch den Glauben auch im Gespräch der christlichen Konfessionen untereinander wieder an Bedeutung gewonnen hat. $\mathrm{Ob}$ die beiden großen Strömungen der westlichen Christenheit - die römisch-katholische Kirche und die reformatorischen Kirchen - auf eine neue ökumenische Gemeinsamkeit zugehen können, entscheidet sich nicht zuletzt an der Frage, ob das Verständnis der Rechtfertigung sie noch in dem Sinn trennt, in dem dies im 16. Jahrhundert von den Reformatoren einerseits, vom 
Trienter Konzil andererseits behauptet wurde. Deshalb ist der Prozeß von großer Bedeutung, durch den man versucht hat, wechselseitige Mißverständnisse abzubauen und im Rückgang auf die biblische Botschaft eine gemeinsame Sprache zu finden, auf deren Hintergrund sich das Gewicht unterschiedlich geprägter Einzelaussagen relativiert.

Der Deutschlandbesuch Papst Johannes Pauls II. im Jahr 1980 hat dazu den äußeren Anstoß gegeben. Eine hochrangig besetzte Theologenkommission klärte daraufhin in sorgfältiger Expertenarbeit, die Jahre in Anspruch nahm, ob die wechselseitigen Lehrverurteilungen, die im 16. Jahrhundert in den reformatorischen Bekenntnisschriften und in den gegenreformatorischen Texten des Konzils von Trient ausgesprochen worden waren, die beiden Seiten auch ein halbes Jahrtausend später noch träfen. ${ }^{23}$ Dabei zeigte sich insbesondere eine Übereinstimmung in der Einsicht, daß die Stellung des Menschen vor Gott sich allein der göttlichen Gnade und nicht den menschlichen Werken verdankt.

Diese Einsicht wurde in der Gemeinsamen Erklärung zur Rechtfertigungslehre aufgegriffen, die zwischen dem Lutherischen Weltbund dem Dachverband lutherischer Kirchen in allen Kontinenten - und der römisch-katholischen Kirche, vertreten durch den Päpstlichen Rat zur Förderung der Einheit der Christen, im Jahr 1997 vereinbart wurde. Diese Erklärung hat eine komplizierte Geschichte; manches an ihrem Inhalt ist bis zum heutigen Tag umstritten. Trotzdem ist ihre gemeinsame Unterzeichnung am 31. Oktober 1999 ein wichtiges und denkwürdiges Datum. Denn damit wird eine Gemeinsamkeit im Verständnis der Rechtfertigung anerkannt, die wichtiger ist als deren unterschiedliche Entfaltung in einzelnen Aussagen. Gemeinsam wird beispielsweise festgestellt:

„Es ist unser gemeinsamer Glaube, daß die Rechtfertigung das Werk des dreieinigen Gottes ist. Der Vater hat seinen Sohn zum Heil der Sünder in die Welt gesandt. Die Menschwerdung, der Tod und die Auferstehung Christi sind Grund und Voraussetzung der Rechtferti-

23 Vgl. K. Lehmann/W. Pannenberg (Hg.), Lehrverurteilungen kirchentrennend?, Freiburg i.Br. 1986 und die daran anschließende Diskussion. 
gung. Daher bedeutet Rechtfertigung, daß Christus selbst unsere Gerechtigkeit ist, derer wir nach dem Willen des Vaters durch den Heiligen Geist teilhaftig werden. Gemeinsam bekennen wir: Allein aus Gnade im Glauben an die Heilstat Christi, nicht aufgrund unseres Verdienstes, werden wir von Gott angenommen und empfangen den Heiligen Geist, der unsere Herzen erneuert und uns befähigt und aufruft zu guten Werken....

Gemeinsam sind wir der Überzeugung, daß die Botschaft von der Rechtfertigung uns in besonderer Weise auf die Mitte des neutestamentlichen Zeugnisses von Gottes Heilshandeln in Christus verweist: Sie sagt uns, daß wir Sünder unser neues Leben allein der vergebenden und neuschaffenden Barmherzigkeit Gottes verdanken, die wir uns nur schenken lassen und im Glauben empfangen, aber nie - in welcher Form auch immer - verdienen können.

Darum ist die Lehre von der Rechtfertigung, die diese Botschaft aufnimmt und entfaltet, nicht nur ein Teilstück der christlichen Glaubenslehre. Sie steht in einem wesenhaften Bezug zu allen Glaubenswahrheiten, die miteinander in einem inneren Zusammenhang $\mathrm{zu}$ sehen sind. Sie ist ein unverzichtbares Kriterium, das die gesamte Lehre und Praxis der Kirche unablässig auf Christus hin orientieren will. Wenn Lutheraner die einzigartige Bedeutung dieses Kriteriums betonen, verneinen sie nicht den Zusammenhang und die Bedeutung aller Glaubenswahrheiten. Wenn Katholiken sich von mehreren Kriterien in Pflicht genommen sehen, verneinen sie nicht die besondere Funktion der Rechtfertigungsbotschaft. Lutheraner und Katholiken haben gemeinsam das Ziel, in allem Christus zu bekennen, dem allein über alles zu vertrauen ist als dem einen Mittler, durch den Gott im Heiligen Geist sich selbst gibt und seine erneuernden Gaben schenkt. “24

Die „Gemeinsame Erklärung“ enthält nicht alles, was im Sinn der Reformation über die Rechtfertigung des Sünders zu sagen ist. Die bebende Erregung, in die Luther zeit seines Lebens durch seine epochale Entdeckung versetzt wurde, ist ihr allenfalls von ferne abzuspü-

\section{Lüning u.a., (Fn. 7), $84 \mathrm{f}$.}


ren. Sie enthält keinen abschließenden ökumenischen Konsens, sondern bildet nur einen Schritt auf diesem Weg. Wie epochal dieser Schritt sein wird, ist heute noch nicht abzusehen. Denn insbesondere im Verständnis des kirchlichen Amtes sind die Kirchen noch nicht wirklich aufeinander zugegangen. Das hierarchische, in der apostolischen Sukzession gegründete Bischofsamt mit dem unfehlbaren Papst an der Spitze gilt nach römisch-katholischer Auffassung nach wie vor als Bedingung einer umfassenden Kirchengemeinschaft. Auch eine vollgültige Abendmahlsgemeinschaft ist von katholischer Seite aus noch an diese Voraussetzung gebunden. Deshalb ist nach wie vor ungewiß, ob mit der Gemeinsamen Erklärung zur Rechtfertigungslehre ein Prozeß eingeleitet wurde, der zu umfassenderer Kirchengemeinschaft führen kann, die wechselseitige Gewährung der Abendmahlsgemeinschaft eingeschlossen. Die Frage ist gerade in Deutschland von großer Bedeutung, wo für das Jahr 2003 ein großer Ökumenischer Kirchentag in Berlin geplant wird.

Aber solche weiterführenden Fragen können die Bedeutung nicht mindern, die der „Gemeinsamen Erklärung" und den sie begleitenden Dokumenten in der Sache zukommt. Auf der Grundlage der Arbeit an dem Dokument „Lehrverurteilungen - kirchentrennend?“ und im Anschluß an andere wichtige Beiträge zum ökumenischen Dialog hält sie als gemeinsame Einsicht fest, daß Gott allein es ist, der die Rechtfertigung des sündigen Menschen bewirkt. Gott nimmt den sündigen Menschen allein durch Gnade und allein im Glauben um Christi willen an und schenkt ihm damit einen Neuanfang in der Gemeinschaft mit Gott wie in der Gemeinschaft mit allen anderen Menschen, die wie er selbst von Gott angenommen sind. Die Macht der Sünde ist durch Jesu Tod und Auferweckung gebrochen; der ,alte Mensch“ wird aus der Sündhaftigkeit befreit und in der Ausrichtung auf Gott erneuert; aber die reale Bedrohung durch die Macht des Bösen ist ständig gegeben, die von den Reformatoren auf die Formel gebracht wird, der Glaubende sei „gerecht und Sünder zugleich“. Aber auch angesichts der Macht der Sünde gilt: Die Bejahung durch Gott ermöglicht die Selbstbejahung ebenso wie die Annahme des andern. 
Gute Werke sind in dieser Perspektive Konsequenzen aus dem Glauben, daß Gott den Menschen um Christi willen angenommen hat. Wie ein Baum Früchte trägt, so folgen gute Werke aus dem Glauben.

Auf der Grundlage dieser Gemeinsamkeiten beschreibt die „Gemeinsame Erklärung zur Rechtfertigungslehre“ die unterschiedlichen Auslegungen, welche die gemeinsam anerkannte Botschaft in der römisch-katholischen wie in der lutherischen Tradition findet. Der Konsens, so wird in diesem Zusammenhang ausdrücklich erklärt, bezieht sich nicht auf alle Einzelheiten, sondern auf „Grundwahrheiten“ der Rechtfertigungslehre. Die Frage, ob entscheidende Differenzen dem angestrebten Konsens geopfert wurden, und umgekehrt die Frage, ob ein Konsens in Grundwahrheiten ausreicht oder ob es nicht mindestens ein Konsens in den Grundwahrheiten sein müsse, bestimmte die Diskussion zu diesem Thema.

$\mathrm{Zu}$ den wichtigsten Resultaten dieser Debatte gehört nach meiner Überzeugung, daß sie eine Verständigung über das ökumenische Modell erbracht hat, an dem die Gemeinschaft zwischen den Kirchen in Zukunft orientiert sein sollte. Es ist nicht das Modell einer Einheitsökumene, sondern das Modell „,versöhnter Verschiedenheit“. In dem Bewußtsein, in Grundwahrheiten übereinzustimmen, bemühen die beteiligten Kirchen sich darum, die verbleibenden Differenzen als Verschiedenheiten zu verstehen, die sich nicht ausschließen, sondern bereichern. Miteinander unterstellen sie sich dem Auftrag, vom christlichen Glauben unter den Bedingungen der Gegenwart gemeinsam Zeugnis abzulegen. Das müßte, so heißt meine Überzeugung, auch zur Folge haben, daß mit den verbleibenden Differenzen insbesondere im Amtsverständnis so umgegangen werden kann, daß diese Differenzen die wechselseitige Gewährung der Abendmahlsgemeinschaft nicht länger ausschließen.

Sucht man abschließend nach einem einfachen Symbol für das, was theologisch in vielen Verästelungen als Lehre von der Rechtfertigung diskutiert wird, so läßt sich dieses Symbol in einem biblischen Gleichnis von großer Überzeugungskraft finden: in dem Gleichnis 
vom verlorenen Sohn. ${ }^{25}$ Der Sohn, der sein Erbteil verpraßt hatte und in großer Armut versunken war, wird vom Vater wieder als Sohn angenommen: „Dieser mein Sohn war tot und ist wieder lebendig geworden; er war verloren und ist gefunden worden“. Nicht seiner Taten wegen wird der Sohn angenommen, aber auch seiner Untaten wegen wird er nicht verworfen. Seine unverlierbare Würde als Sohn verdankt er allein der Güte des Vaters. Daß der Mensch mehr ist, als er selbst aus sich macht, wird in diesem Gleichnis unmittelbar einsichtig. In welch elementarer Weise Humanität daran hängt, daß kein Mensch mit seinen Taten wie mit seinen Untaten identisch ist, zeigt sich im Bild des verlorenen Sohnes über den Abstand der Jahrtausende hinweg. ${ }^{26}$

\section{Rechtfertigung und Recht bei Karl Barth}

In der neueren Diskussion zur Rechtfertigungslehre wie in den Grundaussagen der „Gemeinsamen Erklärung zur Rechtfertigungslehre“ und der sie begleitenden Dokumente tritt der innere Zusammenhang zwischen Rechtfertigung und Recht kaum in den Blick. Beide Bereiche scheinen sich auch nicht unmittelbar zu berühren. Denn das Recht hat es damit zu tun, daß einem Menschen seine Taten zugerechnet werden und er für sie zur Verantwortung gezogen wird. Die Rechtfertigung dagegen hat es damit zu tun, daß wir Menschen für unsere Taten nicht einstehen können, geschweige denn, daß wir mit ihnen eine Anerkennung erwerben, die vor Gott gilt. Unser Leben gelingt vielmehr nur deshalb, weil uns eine Anerkennung zuteil wird, die wir nicht durch unsere Taten erwirken.

Wie verhält sich die Zurechnung unserer Taten nach den Regeln des Rechts zur Anerkennung der menschlichen Person unabhängig von ihren Taten kraft der Rechtfertigung? Das ist die rechtsethische Frage,

25 Lukas 15, 11-32.

26 Vgl. J. Wanke, Die gemeinsame Botschaft für uns heute, in: P. Lüning u.a. (Fn. 7), 41-51 (48 ff.). 
die sich stellt, wenn wir den Zusammenhang von Rechtfertigung und Recht zum Thema machen.

Der aus der Schweiz stammende evangelische Theologe Karl Barth war es, der diese Frage in einer für die Theologie seiner Zeit 'sehr überraschenden Wendung aufgriff. Schon in seiner Ethik-Vorlesung von 1928/29 behandelt er das Recht als diejenige Autorität, welche die Regelung der Kollision zwischen je meinen Interessen und den Interessen der vielen anderen ermöglicht. ${ }^{27}$ Barth vertritt also eine Konflikttheorie des Rechts. Er würdigt das Recht als diejenige Instanz, kraft deren die Anerkennung des andern im Konflikt möglich ist. Theologisch wird das Recht deshalb nicht als Schöpfungsordnung verstanden. Es erschließt seine Bedeutung vielmehr nur im Horizont von Gottes Versöhnungshandeln; es gehört zum Gebot des versöhnenden Gottes.

Das ist der Hintergrund für die Art und Weise, in welcher Karl Barth im Jahr 1938 die rechtsethische Fragestellung zuspitzt. Das geschieht mit folgenden Worten: „Die Frage lautet zunächst: Gibt es eine Beziehung zwischen der Wirklichkeit der von Gott in Jesus Christus ein für allemal vollzogenen Rechtfertigung des Sünders allein durch den Glauben und dem Problem des menschlichen Rechts: eine innere, eine notwendige, eine solche Beziehung, durch die mit der göttlichen Rechtfertigung auch das menschliche Recht in irgendeinem Sinne zum Gegenstand des christlichen Glaubens und der christlichen Verantwortung und damit auch des christlichen Bekenntnisses wird? Gehört das Problem der Ordnung, die nicht mehr oder noch nicht die des Reiches Gottes, das Problem des Friedens, der nicht mehr oder noch nicht der ewige Gottesfriede, das Problem der Freiheit, die nicht mehr oder noch nicht die Freiheit der Kinder Gottes ist - gehört das alles mit hinein in den Bereich der Wirklichkeit der neuen Zeugung des Menschen durch Gottes Wort, in die Wirklichkeit seiner Heiligung durch den Geist? Gibt es bei aller Verschiedenheit in irgendeiner inneren und notwendigen Zugehörigkeit neben dem ... Gottesdienst der

27 K. Barth, Ethik II, 1928/29, hg. von D. Braun, Zürich 1982, 212-237; vgl. H.-R. Reuter, Rechtsethik in theologischer Perspektive. Studien zu Grundlegung und Konkretion, Gütersloh 1996, 102 ff. 
christlichen Existenz und ... neben (dem) ... ,Gottesdienst ${ }^{\star}$ der Gemeinde ... auch so etwas wie einen politischen Gottesdienst, das heißt ... einen Dienst Gottes, der ... in irgendeiner Anerkennung, Förderung, Verteidigung, Verbreitung menschlichen Rechtes nicht trotz, sondern gerade wegen der göttlichen Rechtfertigung bestehen würde?، 28

Der Ausgangspunkt, von dem aus Barth diese Fragen beantwortet, liegt in seinem Verständnis des Bundes, den Gott in Jesus Christus mit dem Menschen schließt. Gott erwählt in seiner Freiheit den Menschen als seinen Bundespartner; auf diesen Grundsatz läßt sich zurückführen, wie Karl Barth Evangelium und Gesetz und damit auch Rechtfertigung und Recht aufeinander bezieht. Es geht um das Verhältnis zwischen dem erwählenden Gott und dem erwählten Menschen. Es ist in der Person Jesu Christi definiert; denn er ist erwählender Gott und erwählter Mensch in einem. ${ }^{29}$ Als Zusage der göttlichen Gnade enthält dieser Bund auch das göttliche Gebot als eine notwendige Implikation in sich. Deshalb geht in Barths Verständnis das Evangelium als Gnadenzusage dem Gesetz als der konkreten Form des göttlichen Gebietens sachlich voraus. Aus demselben Grund geht auch die Rechtfertigung, in der Gott dem Menschen eine ungeschuldete Anerkennung aus Liebe gewährt, dem Recht voraus, das die wechselseitige Anerkennung von Menschen untereinander auch im Konflikt möglich macht. Anders als die lutherische Tradition, die in den Institutionen des menschlichen Rechts Instrumente des göttlichen Strafhandelns sieht und sie dem "politischen Gebrauch des Gesetzes“ zuordnet, nimmt Barth auch das menschliche Recht als Entsprechung zur göttlichen Rechtfertigung wahr. Was dabei unter „Entsprechung“ zu verstehen ist, erläutert er durch eine Verhältnisbestimmung von Kirche und Staat.

Diese Verhältnisbestimmung faßt er in das Bild zweier konzentrischer Kreise. Christengemeinde und Bürgergemeinde stehen zueinander wie ein engerer und ein weiterer Kreis, deren gemeinsamen Mittelpunkt die Zusage der Rechtfertigung und die Verheißung des Reiches Gottes bilden. Auch die Bürgergemeinde hat in diesem letzten Sinn aller

28 K. Barth, Rechtfertigung und Recht (Fn. 8), 5.

29 Vgl. K. Barth, Die Kirchliche Dogmatik, Zürich 1932 ff., II / 2, $101 \mathrm{ff}$. 
geschichtlichen Existenz ihren Mittelpunkt. Aber sie kann ihn nicht ausdrücklich zum Thema machen; sie kann sich nicht zu ihm bekennen. Dieses Bekenntnis geschieht in der Christengemeinde; um dieses Bekenntnisses willen bleiben Christengemeinde und Bürgergemeinde trotz ihres gemeinsamen Mittelpunktes in ihren Radien immer voneinander unterschieden.

Trotz des gemeinsamen Mittelpunktes muß die Rechtsordnung der Bürgergemeinde deshalb so beschaffen sein, daß ihre Verbindlichkeit von den Glaubensüberzeugungen der Bürgerinnen und Bürger unabhängig ist. Denn sie kann nicht ein bestimmtes Bekenntnis für alle verpflichtend machen; vielmehr ist in religiöser Hinsicht Toleranz die letzte Weisheit des Staates.

Wie aber soll dann die Wirklichkeit einer solchen politischen Gemeinschaft auf die rechtfertigende Gnade Gottes bezogen werden? Eben dadurch, so antwortet Barth, daß die Christengemeinde die Notwendigkeit einer staatlichen Ordnung anerkennt und für sie eintritt. Christen sehen in der politischen Ordnung die „Auswirkung einer göttlichen Anordnung“, eine „der Konstanten der göttlichen Vorsehung und Weltregierung in ihrer zugunsten des Menschen stattfindenden Gegenwirkung gegen die menschliche Sünde“ und damit ein „Instrument der göttlichen Gnade" und Geduld. ${ }^{30}$ Von hier aus ergeben sich dann aber auch die „Richtung und Linie“, ${ }^{31}$ in der sich die Christengemeinde an der Erfüllung der Aufgaben beteiligt, die sich der Bürgergemeinde stellen. Barth hat Beispiele für diese „Richtung und Linie" nach dem Modell der Analogie zu entwickeln versucht. Sie sind von sehr unterschiedlicher Qualität und Überzeugungskraft; manche von ihnen erwecken den Anschein, als könne selbst Barth dem Gefälle einer naturrechtlichen Deduktion nur schwer widerstehen. Unklar bleibt auch, inwiefern er aus der Erfahrung der eigenen Zeit geborene Einsichten und Urteile mit dem Anschein des Zeitlosen versieht und als zwingende Analogien zur Offenbarung von Gottes rechtfertigender Gnade ausgibt. Das aber hängt damit zusammen, daß

30 K. Barth, Christengemeinde und Bürgergemeinde (Fn. 8), 54.

31 K. Barth, Christengemeinde und Bürgergemeinde (Fn. 8), 60. 
er zu sehr an einzelnen Analogien orientiert ist, anstatt grundsätzlicher danach zu fragen, welches Bild vom Menschen uns in der Botschaft von der Rechtfertigung des Sünders entgegentritt und was dieses Bild vom Menschen für das Verständnis des Rechts bedeutet. Wendet man jedoch Barths Fragestellung in diese grundsätzliche Richtung, dann verdient seine Verhältnisbestimmung von Rechtfertigung und Recht Zustimmung.

\section{Rechtsethische Konsequenzen}

Der anthropologische Grundsinn der Rechtfertigungslehre besteht darin, daß das Sein des Menschen nicht von seinem Tun, sondern das Tun des Menschen von seinem Sein her begriffen wird. ${ }^{32}$ Der wichtigste Beitrag des Christentums zur Ethik des Rechts liegt in der Unterscheidung zwischen der Person und ihren Taten. Die Gerechtigkeit, die vor Gott gilt, ist nicht durch menschliches Handeln zu erwirken; sie ergibt sich nicht aus der Erfüllung des Gesetzes. Sondern die Gerechtigkeit Gottes ist eine Macht, durch die Gott dem Menschen die Anerkennung zukommen läßt, die er niemals von sich aus erwirken kann. Deshalb ist auch der Sinn menschlichen Lebens nicht das Resultat menschlichen Tätigseins; sondern der Mensch kann gerade deshalb sinnvoll tätig sein, weil er darin einen Sinn bejaht, der seinem Leben ohne eigenes Zutun verliehen ist. Wäre es anders, wäre der Sinn menschlichen Lebens von unserem Handeln abhängig, dann ginge dieser Sinn verloren, wenn unser Handeln scheitern würde und wessen Handeln scheitert nicht? Menschliches Leben ist mehr als die Summe unserer Taten - und deshalb auch mehr als die Summe unserer Untaten. Es ist nicht identisch mit unseren Leistungen - und deshalb auch nicht mit unseren Fehlleistungen. Oder noch knapper gesagt: Der Mensch ist mehr, als er selbst aus sich macht - das ist der Kern der Botschaft von der unverdienten Annahme und unverlierbaren

32 Das ist der Schlüssel zum Verständnis der Rechtfertigungslehre, den Eberhard Jüngel entwickelt: $E$. Jüngel, Das Evangelium von der Rechtfertigung des Gottlosen als Zentrum des christlichen Glaubens, Tübingen 1998. 
Anerkennung des Menschen durch Gottes Gnade. Diesem Bild vom Menschen entspricht ein Rhythmus des Lebens, in dem das tätige Leben aus dem Beschenktwerden hervorgeht, in dem die Arbeitswoche vom Sonntag herkommt und in ihn zurückkehrt, weil das Sein und das Sein-Lassen den Ursprung aller Tätigkeiten bildet.

Aus diesem Bild vom Menschen ergibt sich dann aber insbesondere ein „unbedingter Vorrang der Person vor ihren Werken“. ${ }^{33}$ Dieser Vorrang gilt eben nicht nur im Gottesverhältnis, sondern auch im Verhältnis zur Welt. Dieser Vorrang der Person vor ihren Werken findet auch im neuzeitlichen Rechtsbewußtsein seinen Niederschlag. Der rechtsethische Sinn der Rechtfertigungslehre, der darin zur Geltung kommt, läßt sich so ausdrücken: Kein Mensch kann seine endgültige Anerkennung als Person durch seine Taten erwirken und damit auch nicht durch seine Untaten verwirken. Da der Mensch mehr ist, als er selbst aus sich macht, verfügt er durch das, was er selbst macht oder unterläßt, nicht über sein Personsein. Das Recht hat deshalb seinen entscheidenden Maßstab darin, daß es die Personwürde des Menschen respektiert und dazu hilft, daß Menschen einander in dieser Würde anerkennen und achten. Dieser Gedanke findet seinen zusammenfassenden Ausdruck in der These von der unantastbaren Würde jeder menschlichen Person.

Diese Personwürde stuft sich in keiner Weise nach Maßstäben des Geschlechts oder des Alters, der Fähigkeiten oder des Wohlstands, der Verdienste oder Leistungen $\mathrm{ab}$. Sie gilt gerade unabhängig von allen derartigen Unterschieden.

Dieser Grundgedanke hat in alle modernen Rechtssysteme Eingang gefunden, so weit sie sich von einem radikal gefaßten Gedanken menschlicher Würde bestimmen lassen und deshalb das Recht auf gleiche Anerkennung und Achtung als das grundlegende Recht betrachten. Bei Ronald Dworkin beispielsweise heißt es in diesem Sinn: „Wir können daher sagen, daß die Gerechtigkeit als Fairneß auf der Annahme eines natürlichen Rechts auf gleiche Anerkennung und Achtung beruht, das alle Frauen und Männer besitzen, und zwar nicht

33 E. Jüngel, Das Evangelium von der Rechtfertigung des Gottlosen (Fn. 32), 226. 
kraft ihrer Herkunft oder bestimmter Merkmale oder Verdienste oder Vortrefflichkeit besitzen, sondern einfach deswegen, weil sie menschliche Wesen sind, die die Fähigkeit haben, Pläne zu machen und Gerechtigkeit zu üben. ${ }^{\text {34 }}$ Am Grundsatz der Achtung des Menschen als Menschen, also an dem Respekt vor dem voraussetzungslosen Recht, Rechte zu haben, trennen sich Rechtssysteme von Gewaltsystemen. Immanuel Kant formuliert diesen Grundsatz in einprägsamer Kürze: „Ein jeder Mensch hat rechtmäßigen Anspruch auf Achtung von seinem Nebenmenschen, und wechselseitig ist er dazu auch gegen jeden anderen verbunden. “35

Begründet wird dieses Prinzip wechselseitiger Achtung bei Kant mit einem Begriff menschlicher Würde, nach dem diese gegen kein Äquivalent ausgetauscht werden kann. Hierin ist Kant ein Erbe der jüdischen und christlichen Tradition. Im Blick auf die jüdische Tradition ist es der Berliner Rabbiner und Religionsphilosoph Leo Baeck gewesen, der zu Beginn unseres Jahrhunderts den historischen wie gedanklichen Zusammenhang zwischen dem religiösen Begriff der Gottebenbildlichkeit und dem rechtsethischen Grundbegriff der Menschenwürde hervorhob: „Ein Bund ist zwischen dem Menschen und Gott, ein Bund zwischen der Freiheit und der Ewigkeit, eine Einheit, die in dem $\mathrm{Ge}-$ gensatze lebt. ... Die Heilige Schrift sagt, um dieses Wesen des Menschen zu benennen: Der Mensch ist im Ebenbilde Gottes geschaffen. ... Ein bleibendes Symbol, ein Prinzip des Menschentums, das den religiösen, sittlichen Begriff ,Mensch', den Begriff der Menschheitswürde gibt, ist damit gewonnen. Wie groß immer der Unterschied von Mensch zu Mensch ist, die Gottesebenbildlichkeit ist ihnen allen ihr Charakter, ist ihnen allen gemeinsam; sie ist es, die den Menschen zum Menschen macht, ihn als Menschen bezeichnet.“36

Der christliche Glaube hebt in besonderer Weise hervor, daß die Entsprechung des Menschen zu Gott zwar durch die menschliche Sünde

34 R. Dworkin, Bürgerrechte ernstgenommen, Frankfurt a. M. 1984, 300 - in Korrektur der unzureichenden deutschen Übersetzung.

35 I. Kant, Metaphysik der Sitten. Tugendlehre, $\$ 38$ (Studienausgabe IV, 600).

36 L. Baeck, Das Wesen des Judentums, 6. Aufl. Berlin o. J., 165 f;; vgl. H. Kreß, Menschenwürde im modernen Pluralismus, Hannover 1999, 28 ff. 
zerstört, aber durch die Zuwendung Gottes zu dem in der Sünde in sich selbst verkrümmten Menschen ein für allemal erneuert und bekräftigt wird. Die Einsicht in die Sündhaftigkeit des Menschen verbietet die Vorstellung, als könne der Mensch sich seine Gottebenbildlichkeit selbst erarbeiten und seine Würde selbst verleihen. Die Zusage der göttlichen Gnade aber verbietet den Gedanken, daß ein Mensch durch seine Schuld und durch das Mißlingen seines Handelns sich seiner Würde selbst vollständig entledigt hätte. Der Mensch kann sich seine Würde weder verleihen noch entziehen; er kann sie aber auch keinem andern zu- oder absprechen. Eben deshalb gibt es kein Äquivalent, mit dem sie aufgewogen werden kann.

Die rechtsethische Folgerung heißt: Der Angriff auf die Würde - also auf Leben und Integrität - eines anderen Menschen ist ein Angriff auf die elementaren Grundlagen des Rechts; er muß deshalb eine Reaktion der Rechtsgemeinschaft hervorrufen. Aber Anerkennung und Achtung gebühren jedem Menschen - auch dem noch, der die Würde anderer mißachtet hat. Auch wer sich selbst würdelos verhalten hat, behält den Anspruch auf Achtung seiner Würde. Darin zeigt sich die humane Qualität einer Rechtsordnung. Sie steht nirgendwo mehr auf dem Prüfstand als im Bereich des Strafrechts, des Strafprozesses wie des Strafvollzugs.

Nur soweit es um eine derartige humane Qualität der Rechtsordnung geht, kann von Rechtsethik in einem strikten Sinn die Rede sein. Nur diesseits des Tötungsverbots läßt sich diese humane Qualität wahren. Deshalb markiert das Gebot „Du sollst nicht töten“ ebenso wie für das individuelle Handeln so auch für die staatliche Rechtsordnung eine unüberschreitbare Grenze.

Würde kommt allen Menschen unbeschadet ihrer Unterschiede in gleicher Weise zu. Aber der Umgang des Menschen mit der eigenen Würde wie mit der Würde anderer vollzieht sich in der konkreten Welt all solcher Unterschiede; der Respekt vor der Würde des Menschen schließt die Achtung seiner Individualität und Unverwechselbarkeit, damit aber auch die Achtung seiner Endlichkeit und Begrenztheit ein. Zur Individualität und Unverwechselbarkeit der Menschen und insofern auch zu ihrer Würde gehört insofern auch, daß 
ihnen ihre Taten zugerechnet, ihre Fehlleistungen vorgehalten und ihre Leistungen anerkannt werden. Es wäre ja auch ein offenkundiger Angriff auf die Würde des Menschen, wenn seine Verantwortung für die eigenen Taten wie die eigenen Untaten schlechterdings abgestritten und ignoriert würde; insofern gehört auch Schuldfähigkeit zur Würde des Menschen.

Aber das geschieht alles unter der Voraussetzung, daß in jedem Menschen eine Person gesehen wird und eben nicht nur ein Täter oder Untäter. Keine noch so „übermenschliche“ Tat gibt deshalb einen Anlaß, eine Person so mit ihrer Tat zu identifizieren, daß wir sie zum „Übermenschen“ erklären; und keine noch so „unmenschliche“ Tat kann es rechtfertigen, daß wir eine Person vollständig mit ihrer Tat gleichsetzen und deshalb zum „Unmenschen“ erklären. In beiden Hinsichten gilt vielmehr der Satz: „Die Würde des Menschen ist unantastbar. Sie zu achten und zu schützen ist Verpflichtung aller staatlichen Gewalt. “37

Man übergeht in der rechtsethischen und verfassungsrechtlichen Debatte zumeist die Verwurzelung dieses Grundsatzes im Zusammenhang von Rechtfertigung und Recht. Das geschieht aus naheliegenden Gründen. Die säkulare Rechtsordnung entfaltet ihre verpflichtende Wirkung unabhängig von religiösen Voraussetzungen und weltanschaulichen Vorgaben. Sie muß insofern auch einer säkularen Interpretation zugänglich sein. Nichtreligiöse Interpretationen des Menschenwürdegedankens können und dürfen insofern in ihrer Legitimität nicht bestritten werden. Aber zugleich ist der Hinweis nötig: Eine radikal gedachte Vorordnung der Person vor ihre Taten läßt sich ohne einen expliziten Gottesbezug nur schwer, wenn überhaupt begründen. ${ }^{38}$ Ein Begriff der menschlichen Würde, der nicht in einem besonderen Vermögen des Menschen begründet ist und deshalb auch jede Abstufung dieser Würde gemäß den unterschiedlichen Ausprägungen dieses Vermögens abwehrt, ist nur begründbar, wenn der Mensch in

\section{Art. 1 Abs.1 GG.}

38 Michael Perry hat daraus den unausweichlich religiösen Charakter des Gedankens der Menschenrechte abgeleitet: M. J. Perry, The Idea of Human Rights. Four Inquiries, New York/Oxford 1998. 
seinem Sein auf ein anderes seiner selbst, eben auf die Wirklichkeit Gottes bezogen ist. Deshalb erweist sich der Gedanke der Entsprechung des Menschen zu Gott, also der Gedanke der Gottebenbildlichkeit, als Schlüssel zum Verständnis menschlicher Würde.

Diese Würde ist wirklich radikal gedacht; sie kommt den Menschen unabhängig von ihren Taten wie von ihrem Glauben zu. Ob ein Mensch sich selbst reflexiv zu dem gerade beschriebenen Grund seiner Würde ins Verhältnis setzt, hat keine Auswirkung darauf, ob ihm diese Würde zukommt. Für alle gilt in gleicher Weise der Vorrang der Person vor ihren Taten. Dieser Vorrang schließt, so läßt sich dieser Gedanke auch auf andere Weise zusammenfassen, das Recht der Gewissens- und Religionsfreiheit als ein fundamentales Grundrecht ein. Deshalb ist es kein Zufall, daß in der Reformation beides zugleich entdeckt wurde: das Evangelium der Rechtfertigung und das Grundrecht auf die Freiheit des Gewissens und der Religion.

Die praktischen Auswirkungen des hier entfalteten Gedankens gehen darüber aber weit hinaus. Ich erwähne nur das staatliche Strafrecht mitsamt dem Strafvollzug als ein sehr illustratives Beispiel dafür, was es bedeutet, den Vorrang der Person vor ihren Taten anzuerkennen. $\mathrm{Da}$ auch dem straffällig Gewordenen eine unantastbare Würde zukommt, bildet den entscheidenden Grund dafür, daß die Todesstrafe nicht zu den Möglichkeiten staatlichen Strafens gehört. Daß die Würde der Täter im Strafrecht ebenso zur Geltung kommen muß wie die Würde der Opfer, hat ebenfalls hierin seinen Grund. ${ }^{39}$ Ebenso zeigt sich im Umgang einer Gesellschaft mit denen, die in ihrer eigenen Leistungsfähigkeit eingeschränkt sind oder durch die Umstände an eigener Leistung gehindert sind, ob diese Gesellschaft den Vorrang der Person vor ihren Taten verstanden hat. Das Verhältnis der Gesellschaft zu Kindern und Alten, zu Behinderten und Kranken, aber auch zu Arbeitslosen und Sozialhilfebedürftigen empfängt daraus seine spezifische Beleuchtung und Begründung. Schließlich aber kann die Unterscheidung zwischen einer Person und ihren Taten auch dazu

39 Dazu ausführlicher W. Huber, Sicherheit und Freiheit. Theologisch-ethische Überlegungen zu Strafe und Sicherheitsverwahrung, MS 2000. 
verhelfen, die Leistungen eines Menschen ins rechte Licht zu rücken und auch bei Mächtigen und Einflußreichen die Taten zu würdigen und nicht nur die Untaten zu beleuchten, die dann der verbreiteten Verachtung ,derer da oben“ eine willkommene Bestätigung liefern.

Ist es an der Zeit, so habe ich gefragt, den inneren Zusammenhang zwischen Religion und Recht neu ins Bewußtsein zu heben? Ich habe dafür zunächst zwei Gründe genannt: Zum Gespräch mit anderen Rechtskulturen und der Rolle von Religion in ihnen werden wir nur fähig sein, wenn wir diesen Zusammenhang auch in der eigenen Rechtskultur nicht verdrängen. So hieß die eine Antwort, der ich die zweite Antwort hinzufügte: Wenn wir im Zeitalter der Globalisierung auf planetarische Rechtsstrukturen sinnen wollen, müssen wir auch die Frage nach deren Verankerung in einem planetarischen Ethos neu stellen.

Inzwischen hat sich aus unseren Überlegungen eine dritte Antwort ergeben, die vielleicht beides miteinander verbindet: die Aufmerksamkeit für die Besonderheiten unserer Tradition und den Beitrag zu dem planetarischen Recht, das heute notwendig ist. Das Verbindende liegt in einem Menschenbild des Rechts, das seine radikale Begründung im Gedanken der Rechtfertigung findet: in der Vorordnung der Person vor ihre Taten, in der Anerkennung einer gleichen Würde jeder menschlichen Person, die Respekt fordert unabhängig von all dem, was Menschen voneinander unterscheidet. Der Pluralität, in der Menschen leben und ihr Leben gestalten, werden wir nur gewachsen sein, wenn wir die Gleichheit der Würde achten, die sie zu Menschen macht. Darin liegt die Bedeutung des Themas „Rechtfertigung und Recht" für die Rechtskultur des 21. Jahrhunderts. 


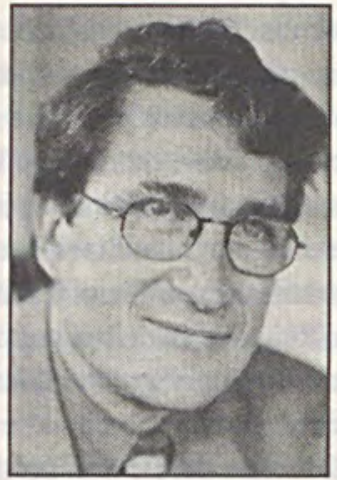

\section{Wolfgang Huber}

\begin{tabular}{|c|c|}
\hline & \\
\hline & eologie in Heidelberg, Göttingen und Tübingen \\
\hline 966 & otion, dann Vikar und Pfarrer in Württemberg \\
\hline & $\begin{array}{l}\text { itarbeiter und stellvertretender Leiter der Forschungsstätte der } \\
\text { vangelischen Studiengemeinschaft in Heidelberg }\end{array}$ \\
\hline 197 & \\
\hline & der Sozialethik an der Unuversit. \\
\hline 5 & ges \\
\hline $07-1$ & elberg \\
\hline 85 & a/USA \\
\hline 5 & ischof der Evangelischen Landeskirche in Berlin-Brandenburg \\
\hline sett 1 & $\begin{array}{l}\text { Honorar-Professor an der Humboldt-Universität zu Berlin und der } \\
\text { Universität Heidelberg }\end{array}$ \\
\hline & Mitglied des Rates der Evangelischen Kirche Deutschalnd \\
\hline 17 & $\begin{array}{l}\text { Mitglied des Zentral- und des Exekutivausschusses des Ökumeni } \\
\text { Rates der Kirchen }\end{array}$ \\
\hline
\end{tabular}

\section{Neueste Buchveröffentlichungen}

- Gerechtigkeit und Recht, Grundlinien christlicher Rechtsethik, Gütersloh 1996

- Zur Freiheit berufen. Biblische Einsichten, Gütersloh 1996, 2. Aufl. 1999

- Meine Hoffnung ist größer als meine Angst. Ein Bischof zu Glauben, Kirche und Gesellschaft, Interviews mit Stefan Berg, Berlin 1996

- Kirche in der Zeitenwende, Gütersloh 1998, TB 1999 


\section{Würzburger Vorträge zur Rechtsphilosophie, Rechtstheorie und Rechtssoziologie}

Heft 1: Arthur Kaufmann: Theorie der Gerechtigkeit. Problemgeschichtliche Betrachtungen, 1984, 51 S., 19,80 DM

Heft 3: Niklas Luhmann: Die soziologische Beobachtung des Rechts, 1986, 48 S., 16,80 DM

Heft 4: Ernst-Wolfgang Böckenförde: Die verfassunggebende Gewalt des Volkes - Ein Grenzbegriff des Verfassungsrechts, 1986, 34 S., $16,80 \mathrm{DM}$

Heft 5: Ralf Dreier: Rechtsbegriff und Rechtsidee. Kants Rechtsbegriff und seine Bedeutung für die gegenwärtige Diskussion, 1986, 37 S., $18,80 \mathrm{DM}$

Heft 6: Günter Dux: Der Täter hinter dem Tun. Zur soziologischen Kritik der Schuld, 1988, 58 S., 24,- DM

Heft 7: Franz Bydlinski: Recht, Methode und Jurisprudenz, 1987, 46 S., $19,80 \mathrm{DM}$

Heft 8: Martin Kriele: Freiheit und „Befreiung“. Gibt es eine Rangordnung der Menschenrechte?, 1988. 52 S., 26,-DM

Heft 9: Manfred Rehbinder: Fortschritte und Entwicklungstendenzen einer Soziologie der Justiz, 1989, 63 S., 26,- DM

Heft 10: Klaus Lüderssen: Die Krise des öffentlichen Strafanspruchs, 1989, 62 S., 26,- DM

Heft 11: Norbert Hoerster: Verteidigung des Rechtspositivismus, 1989, 31 S., 26,- DM

Heft 12: Guiseppe Duso: Der Begriff der Repräsentation bei Hegel und das moderne Problem der politischen Einheit, 1990, 55 S., 24,- DM

Heft 13: Otfried Höffe: Gerechtigkeit als Tausch? Zum politischen Projekt der Moderne, 1991, 37 S., 18,-- DM

Heft 14: Klaus F. Röhl: Die Gerechtigkeitstheorie des Aristoteles aus der Sicht sozialpsychologischer Gerechtigkeitsforschung, 1992, 59 S., 26,- DM 


\section{Würzburger Vorträge zur Rechtsphilosophie, Rechtstheorie und Rechtssoziologie}

Heft 15: Hans Albert: Rechtswissenschaft als Realwissenschaft. Das Recht als soziale Tatsache und die Aufgabe der Jurisprudenz, 1993, 37 S., 19,- DM

Heft 16: Gerd Irrlitz: Moral und Methode. Die Struktur in Kants Moralphilosophie und die Diskursethik, 1994, 56 S., 26,- DM

Heft 17: Hasso Hofmann: Gebot, Vertrag, Sitte. Die Urformen der Begründung von Rechtsverbindlichkeit, 1993, 49 S., 26,- DM

Heft 18: Klaus Adomeit: Das bürgerliche Recht, das Bürgerliche Gesetzbuch und die bürgerliche Gesellschaft, 1996, 42 S., 26,DM

Heft 19: Wolgang Schild: Schuld und Unfreiheit. Gedanken zur Strafjustiz und Psychoanalyse in Leonhard Franks »Die Ursache«, 1996, 50 S., 26,- DM

Heft 20: Kurt Seelmann: Theologie und Jurisprudenz an der Schwelle zur Moderne. Die Geburt des neuzeitlichen Naturrechts in der iberischen Spätscholastik. 1997, 36 S., 22,- DM

Heft 21: Winfried Brugger: Menschenwürde, Menschenrechte, Grundrechte. 1997, 54 S., brosch., 28,- DM

Heft 22: Michael Stolleis: Rechtsgeschichte als Kunstprodukt. Zur Entbehrlichkeit von „Begriff“ und „Tatsache“, 1997, 30 S., brosch., 24,- DM

Heft 23: Gertrude Lübbe-Wolff: Recht und Moral im Umweltschutz. 1999, 49 S., brosch., 28,- DM

Heft 24: Robert Walter: Hans Kelsens Rechtslehre. 1999, 37 S., brosch., 26,- DM

Heft 25: Stefan Breuer: Georg Jellinek und Max Weber. Von der sozialen zur soziologischen Staatslehre, 1999, 39 S., brosch., 26,-DM 